CuPAUAM 25.1, 1999, pp. 75-129

\title{
LA FACTORIA DE SALAZONES DE BAELO CLAUDIA (TARIFA, CÁDIZ). BALANCE HISTORIOGRÁFICO Y NOVEDADES EN LA INVESTIGACIÓN ${ }^{[1]}$
}

\author{
Alicia Arévalo GonZález \\ Darío Bernal Casasola \\ Departamento de Historia, Geografía y Filosofía \\ Universidad de Cádiz
}

\section{Resumen}

Presentamos en este trabajo los primeros resultados arqueológicos obtenidos del estudio de la factoría de salazones de la ciudad hispanorromana de Baelo Claudia realizado con motivo del I Curso Internacional de Arqueología Clásica desarrollado en el citado Conjunto Arqueológico de la Consejería de Cultura de la Junta de Andalucía durante el verano del año 2000. Se realiza en primer lugar un balance historiográfico sobre el conocimiento del "barrio industrial" de este yacimiento del Conventus Gaditanus, atendiendo únicamente a los trabajos que han realizado un tratamiento monográfico sobre esta cuestión. A continuación se procede a realizar un balance de los conocimientos previos derivados de las investigaciones arqueológicas realizadas en esta parte de la ciudad hasta finales de los años noventa. Por último, se presentan parcialmente las primeras conclusiones históricoarqueológicas obtenidas por el equipo de investigación de la UCA, aplicándolas a una parte de los conjuntos industriales estudiados monográficamente, concretamente los denominados Conjunto I y Conjunto IV en la bibliografia más reciente. De manera intercalada en el texto se plantean las posibles líneas de actuación para el futuro de cara a un conocimiento exhaustivo de una de las factorías mejor conservadas, en extensión y entidad de sus estructuras, de todo el Imperio Romano.

\begin{abstract}
We present in this paper the first archaeological results from the recent study carried out in the Salting fish factory of the hispanorroman city of Baelo Claudia, developed during the I International Course in Classical Archaeology in this well known "Conjunto Arqueológico" (Consejería de Cultura, Junta de Andalucía), which has taken place during the summer of 2000. First of all, we take in consideration the historiographical information published concerning the "industrial quarter" of this site located in the Conventus Gaditanus, using mainly those publications that focused in this subject from a monographic point of view. Secondly an up-to-date of the archaeological information by these former studies is provided. In a third place the first archaeological conclusions obtained by the research team of the UCA are exposed, focusing on two of the factories already published, known as "Conjunto I" and "Conjunto IV" in the selected bibliography. At last the working lines for the future are planned trying to achieve a whole knowledge of one of the best preserved fish factories in the Roman world in the next years.
\end{abstract}

[1] Este trabajo ha sido realizado dentro del marco de desarrollo del Grupo de Investigación HUM-671 de la Junta de Andalucía. 


\section{INTRODUCCIÓN}

Durante el mes de julio del año 2000 ha tenido lugar en el Conjunto Arqueológico de Baelo Claudia la celebración del I Curso Internacional de Arqueología Clásica, coorganizado por la Universidad de Cádiz y por la Consejería de Cultura de la Junta de Andalucía $^{[2]}$. Asimismo han colaborado el Instituto de Estudios Ceutíes y la Sociedad Española de Estudios Clásicos ${ }^{[3]}$, esta última otorgando sendas becas a dos alumnos universitarios. Este curso tenía como principales objetivos posibilitar el desarrollo de actividades arqueológicas para completar la formación teórico-práctica de los alumnos universitarios españoles y extranjeros y, en segundo lugar, desarrollar una vía de investigación alternativa en Arqueología Clásica en la provincia de Cádiz, centrada en el estudio de las salazones gaditanas en época romana, aspectos ambos que han sido cubiertos con creces tras la realización de la mencionada actividad, y que se traducirán en una segunda edición durante el año $2001^{14]}$.

El yacimiento gaditano elegido constituye por naturaleza el lugar más apropiado para vincular actividades docentes e investigadoras del Área de Arqueología de la Universidad de Cádiz con la Consejería de Cultura de la Junta de Andalucía. En primer lugar, por su proximidad; en segundo término, por tratarse de una de las ciudades hispanorromanas mejor conocidas científicamente en ámbito nacional e internacional, gracias a las sucesivas campañas de excavación acometidas por la Casa Velázquez; en tercer lugar, por presentar notables expectativas científicas, al ser la factoría de salazones de Baelo una de las más importantes en época romana de todo el Occidente mediterráneo y, por último, por tratarse de un Conjunto Arqueológico que cuenta con la infraestructura necesaria para llevar a buen término los objetivos planteados.

Las actividades de campo practicadas han sido enfocadas en dos líneas perfectamente diferenciadas: por una parte el reestudio planimétrico de la factoría de salazones y por otra la realización de diversas prospecciones arqueológicas en diversos puntos del territorivm vinculado a esta ciudad hispanorromana. Los resultados de estas últimas, que han deparado el hallazgo de un yacimiento de época prerromana y de clara filiación púnica, así como la localización de un asentamiento periurbano del tipo villa como hallazgos más significativos, han sido recientemente presentados a las VIJornadas de Historia del Campo de Gibraltar (Arévalo, Bernal y Lorenzo 2001, 115-132).

[2] Queremos agradecer las facilidades prestadas en todo momento para el desarrollo de esta actividad a la Ilma. Sra. J. Caro, Delegada Provincial de Cultura de la Junta de Andalucía en Cádiz, a D. M. García León, Jefe del Dpto. de Protección e Investigación del Patrimonio Histórico y muy especialmente a D. A. Álvarez Rojas, Director del Conjunto Arqueológico y Codirector de este Curso Internacional. Asimismo, a F. Alarcón, Arqueólogo del Conjunto Arqueológico, por sus atenciones en todo momento. Por último, a L. Aguilera y L. Lorenzo, técnicos-arqueólogos, por su inestimable colaboración en el trabajo de campo.

[3] Desde estas líneas queremos mostrar nuestro explícito agradecimiento a ambas instituciones por su colaboración y patrocinio, que han contribuido considerablemente al éxito de esta actividad de extensión universitaria.

[4] Recientemente ha sido publicada una reseña con la información general de esta actividad en la que se pueden ampliar los resultados de las actuaciones arqueológicas acometidas (Arévalo, Bernal y Álvarez 2000, 270-271). 
En este trabajo presentamos por primera vez los resultados científicos preliminares obtenidos del nuevo estudio arqueológico de la factoría de salazones realizado por la UCA, prestando especial atención a tres cuestiones desglosadas en los respectivos apartados de este trabajo. En primer lugar se realiza un balance historiográfico del conocimiento de la factoría de salazones de Baelo atendiendo a aquellas publicaciones que han tratado la cuestión de manera monográfica, desde los inicios de las intervenciones arqueológicas en la ciudad hasta finales de los años noventa. A continuación se realiza un estado de la cuestión de aquellos aspectos científicos derivados de los estudios citados, prestando especial atención a las conclusiones histórico-arqueológicas sobre el denominado "barrio industrial" de Baelo Claudia, que son los que han marcado el conocimiento actual que tenemos de una de las factorías de salazones mejor conocidas de todo el Imperio romano. En el tercer apartado se presentan los resultados preliminares de las actuaciones arqueológicas realizadas por nosotros en el Conjunto Arqueológico, atendiendo a la revisión planimétrica del sector industrial, a la definición de las unidades funcionales dentro de éste, así como al estudio e interpretación de los conjuntos denominados Conjuntos I y IV de la factoría en la bibliografía de referencia, sintetizando en ellos las precisiones arqueológicas que hoy por hoy podemos plantear sobre la factoría baelonense. Se ha optado por plantear al hilo del discurso una serie de líneas de trabajo para el futuro que pensamos pueden contribuir al conocimiento de esta factoría y, por extensión de los conjuntos industriales urbanos en el "Círculo del Estrecho" y, en general, en la Pars Occidentis del Imperio ${ }^{[5]}$.

\section{UN BREVE RECORRIDO HISTORIOGRÁFICO POR LA FACTORÍA DE SALAZONES DE BAELO CLAUDIA}

La factoría de salazones de Baelo Claudia es, a tenor de la bibliografía existente, el ejemplo mejor conocido de factoría de salazón de todo el occidente mediterráneo, paradigma surgido, sin duda alguna, de la proyección panmediterránea de los famosos trabajos de investigación realizados por M. Ponsich y M. Tarradell en un primer momento (1965), y más tarde por el primero de los investigadores citados en solitario (Ponsich 1988). Huelga insistir sobre una cuestión ampliamente conocida por la investigación especializada, que encuentra en las citas de R. Curtis (1991, 51-53) o más recientemente las de R. Etienne, Y. Makaroun y F. Mayet (1994, 115-119) unos referentes clarividentes al respecto.

La importancia de las factorías de salazones de Baelo Claudia aparece reflejada en la bibliografía sobre este yacimiento, pues en prácticamente todos los trabajos de investigación realizados se alude a las excelencias pesqueras de la zona y, de manera más o menos explícita, al origen de este asentamiento hispanorromano al amparo de la explotación de los recursos derivados de la pesca y del mar. A continuación recogemos únicamente

[5] Los resultados incluidos en estas páginas fueron presentados inicialmente en el Curso denominado "Salazones y conservas de pescado de la Bética en época romana: una visión actual desde la arqueología", organizado por los firmantes dentro de los V Cursos de Otoño de la Universidad de Cádiz en Jerez de la Frontera (septiembre de 2000), así como en la ponencia presentada a las I Jornadas Cordobesas de Arqueología Andaluza organizadas por el Seminario de Arqueología de la Universidad de Córdoba (noviembre de 2000). 
aquellos trabajos que han dedicado una atención especial a la problemática de las industrias de salazón baelonenses, siguiendo para ello un hilo discursivo cronológico en la presentación de la documentación. De esta manera, será posible más adelante evaluar en su justa medida las contribuciones de cada investigador $\mathrm{y}$, al mismo tiempo, la génesis de la problemática actual que presenta el estudio de la factoría de salazones baelonense.

Resulta de interés señalar que los primeros trabajos arqueológicos en Bolonia, realizados hacia 1870 por el capitán de aduanas Félix González, sacaron ya a la luz algunas piletas de salazones (Sillières 1995, 43). Asimismo, el padre Jules Furgus (1907, 149-160; 1908, 205-217), un jesuita belga, que excavó en 1907 un gran número de tumbas, hizo referencia a la existencia de piletas de salazones, aunque él las denominaba erróneamente almadrabas.

Pero el primer gran impulso de la investigación arqueológica de Baelo Claudia y a su vez de la factoría de salazones de esta ciudad fue acometido por P. París, quien ya en su primera visita a Bolonia, realizada en 1914, cuyas impresiones fueron publicadas en el Bulletin Hispanique (París 1917, 221-242), descubrió diversas cubetas destinadas al procesado de la salazón de pescado. Más tarde, entre los años 1917 y 1921, el equipo dirigido por P. París, G. Bonsor y otros investigadores realizó cuatro campañas arqueológicas en la zona pública de la ciudad y en la necrópolis este, que supusieron un auténtico empuje para el conocimiento de Baelo Claudia, máxime si tenemos en cuenta la celeridad con que se publicaron todas estas investigaciones: primero, a través de unos breves informes, y unos años más tarde en las respectivas monografias sobre las excavaciones en la ciudad (París et alii 1923), y en la necrópolis (París et alii 1926). Durante las dos primeras campañas se sacaron a la luz tres fábricas de salazones, situadas en la zona meridional de la ciudad, dos de ellas al oeste de la Calle de las Columnas y otra al este de esta misma arteria viaria. Más tarde, durante las excavaciones acometidas en la campaña de 1919 se descubrió parte de otra fábrica emplazada igualmente al oeste de la Calle de las Columnas y por encima de la denominada Casa del Oeste (figura 1).

La primera fábrica excavada fue la que da al cardo que viene del foro, el hoy denominado Conjunto $\mathrm{V}^{[6]}$, y la describe como una fábrica emplazada sobre una terraza artificial, cuya construcción es posterior a la realización del tramo sur de la muralla, al estar adosada a ella todas las salas. Para dar acceso a esta instalación se abriría una puerta en la muralla que permitiría entrar en la sala 10 , donde se realizarían el despiece y limpieza del pescado; a la derecha, la sala 11 serviría de almacén y, a continuación se situaría el área de salazones, con piletas al este y al sur; a la izquierda de la sala 10 se encuentran dos salas, $\mathrm{n}^{\circ} 8$ y 9 , que constituirían el límite oeste de la fábrica; en la sala 8 señala la existencia, en el muro del fondo y a ras del suelo, de una losa de $25 \mathrm{~cm}$. sin especificar su uso. París seguidamente describe los espacios emplazados al oeste de esta fábrica, los $\mathrm{n}^{\circ} 1 \mathrm{al} 7$, pero sin analizar su funcionalidad. Al norte de la Casa del Oeste tan sólo se pudieron excavar

[6] La nomenclatura que utilizamos en este trabajo para la definición de las factorías de salazón es la planteada por P. Sillières $(1995,166)$, al ser la más coherente con la realidad física del yacimiento, el cual definió las seis factorias exhumadas en el barrio meridional de la ciudad como Conjuntos Industriales I a VI $(=\mathrm{C} . I$ a C. VI). 


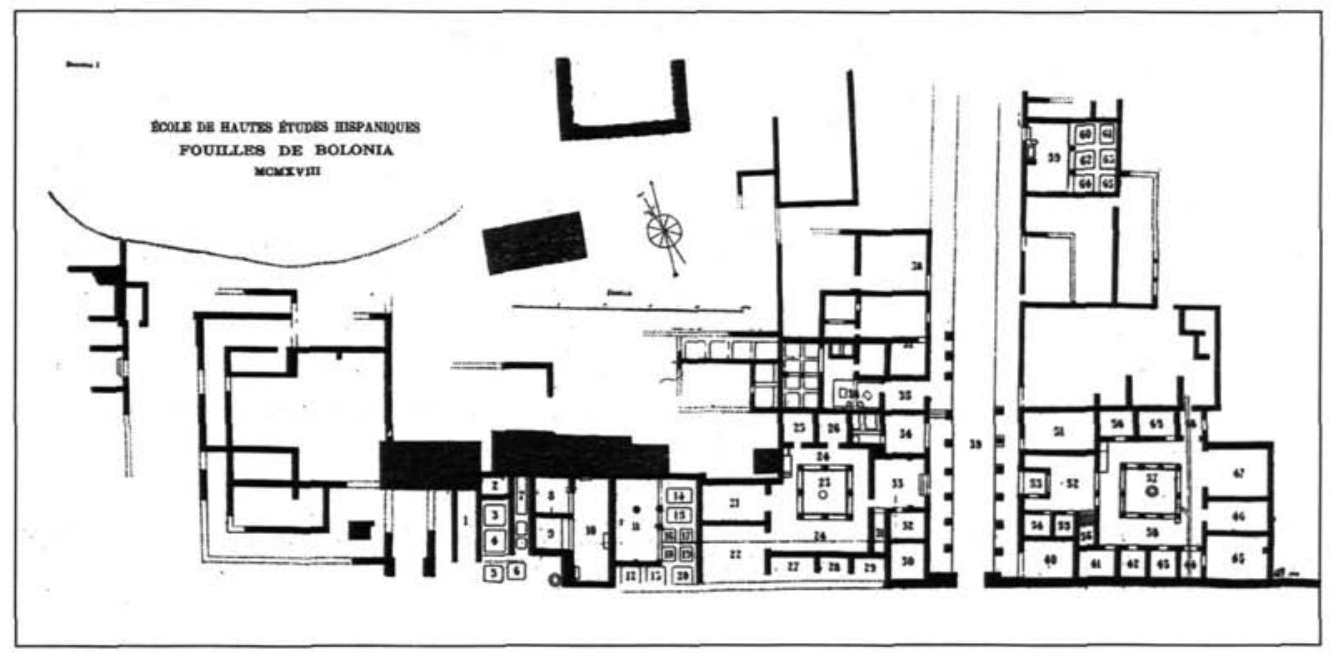

Figura 1. Planimetría de la factoría de Baelo en 1918 según P. Paris (1923, pl. 1)

las seis piletas situadas en el ángulo nordeste del actualmente definido como Conjunto VI. Por el contrario, sí se pudo exhumar la totalidad de la fábrica vecina, abierta a la Calle de las Columnas a través de la sala $\mathrm{n}^{\circ} 35$. Si bien París pensaba que esta sala y la contigua, la $n^{\circ} 36$, donde se excavaron dos aljibes gemelos bajo el suelo, era una tienda con sus almacenes, similar a la emplazada al lado de la Casa del Oeste, la $\mathrm{n}^{\circ} 34$ del plano. Por último, estos primeros trabajos arqueológicos sacaron a la luz la totalidad de la fábrica situada al este de la Calle de las Columnas, que es descrita como una pequeña fábrica compuesta por una gran sala, la $n^{\circ} 59$, donde se prepararían las conservas, que presenta un corto banco de piedra a la derecha de la puerta de entrada, hoy perdido, además de una pequeña pileta $\mathrm{y}$, al fondo un área de saladeros compuesta por seis piletas, $\mathrm{n}^{\circ} 60$ a 65 . A pesar de todos estos trabajos arqueológicos, casi no llegaron a excavarse totalmente las unidades de producción, limitando la acción al seguimiento de muros mediante la realización de zanjas y extrayendo la tierra sin atención expresa a la estratigrafía, como corresponde a la época tan temprana de realización de estas intervenciones; de ahí que la cronología derivada de estas actuaciones sea casi inexistente y muy imprecisa.

El conocido estudio de M. Ponsich y M. Tarradell (1965) constituyó un verdadero hito para la valoración macroespacial de la importancia de las salazones en la economía hispanorromana de esta zona, si bien en el caso de las factorías de Baelo Claudia no aportan grandes novedades respecto a las valoraciones conocidas desde la época del hallazgo de los conjuntos industriales. Sí mencionan explícitamente la existencia de tres "fábricas" de salazón, las cuales aparecen divididas entre sí por sendos ejes viarios, el ya conocido como la "Calle de las Columnas" y otro situado más al oeste. Dentro de estos núcleos habitacionales se advierten cinco conjuntos industriales, que son los que numeran en la planta de hallazgos publicada, la cual está realizada sobre la base planimetríca publicada cuarenta años antes por G. Bonsor (Ponsich y Tarradell 1965, 85-88, fig. 53). Por último, proponen 
una cronología imprecisa pero situada en un histograma horizontal entre mediados del s. I a.C. y principios del s. V d.C. (Ponsich y Tarradell 1965,118, fig. 59), siendo esta propuesta totalmente novedosa para la fecha tan temprana de publicación de esta obra de síntesis.

Tras esta primera etapa, no será hasta mediados de los años sesenta cuando el equipo encabezado por C. Domergue de la Casa de Velázquez aborde la problemática de la historia de la ciudad, a través de un ambicioso proyecto que se materializó en un análisis profundo y en sondeos arqueológicos en numerosos lugares del recinto urbano de Baelo Claudia, tanto en el interior como al exterior de la muralla, con el fin de obtener una estratigrafía lo más completa posible. Estos trabajos dieron lugar a una memoria de conjunto, el número I de la serie de Belo (Domergue 1973), así como a diversas publicaciones (Domergue et alii 1974). Los sondeos realizados se desarrollaron básicamente en la parte central de la ciudad, alrededor de los tres templos que había ya excavado París y, en la ciudad baja, formada por una larga plataforma cortada en dos por el arroyo de las Villas. En esta última zona, que es ahora la que nos interesa, se realizaron tres sondeos durante la primera campaña de 1966: en la plaza de la aldea de Bolonia (sondeo 29), al oeste de las casas de esta misma aldea (sondeo 26) y, al oeste del arroyo de las Villas (sondeo 25), este último localizado ya fuera de la muralla de la ciudad. Fue aquí, en el sondeo 25, donde se halló un depósito de salazones de pescado, con paredes revestidas de opus signinum, que estaba relleno de material fechable en el siglo I d.C., si bien no se llegó al fondo del mismo.

En la segunda campaña de 1966 se ampliaron los sondeos 25, 26 y 29 y se llevaron a cabo otras seis nuevas catas estratigráficas en la ciudad baja: tres en el interior de la muralla (sondeos 36, 40 y 41) y, tres al oeste del arroyo de las Villas (sondeos 30, 31 y 32). De todos estos sondeos cabe destacar la localización, en el nivel $\mathrm{Vb}$ del sondeo 29 , de un depósito de salazones fechable a finales de la República. Dos nuevas piletas se detectaron en el nivel V del sondeo 40, datado en la segunda mitad del siglo I a.C., donde además se halló un fragmento de tubería de desagüe relacionada con los depósitos de salazones. Por otro lado, un conjunto de cuatro piletas se documentó en los niveles IIIa y IIIb del sondeo 31; la más grande parece que fue construida en el siglo I, mientras que las otras tres se levantaron sobre un depósito fechado en época de Claudio que fue nivelado para recibir las piletas (Domergue 1973, 91-92). Por último, en el nivel IIb del sondeo 32 se documentó un nuevo depósito de salazones de una fecha posterior a la primera mitad del siglo I; asimismo en el nivel IV de este mismo sondeo se hallaron multitud de vértebras y de aletas de atún (Domergue 1973, 97-100).

De los resultados de estos trabajos arqueológicos en la llamada ciudad baja se extrajeron las siguientes conclusiones: primero, el motivo del primer establecimiento en Baelo estuvo estrechamente vinculado con las instalaciones industriales documentadas en esta zona de la ciudad. Segundo, los niveles más antiguos se hallaron en la orilla derecha del arroyo de las Villas, donde se localizaron una serie de piletas de salazones (sondeos 29 VIa y Vb y 40 VI), que están en uso desde finales del siglo II a.C. o principios del I a.C. hasta la segunda mitad del siglo I a.C. Dichas instalaciones industriales fueron destruidas y colmatadas quizás para dotar a este lugar otra función vinculada con el crecimiento de la zona de hábitat, aunque también se ha interpretado su destrucción como resultado de los acontecimientos vinculados a las guerras civiles (Domergue 1973, 102). Igualmente parece 
que pudo haber un desplazamiento de la actividad industrial hacia la orilla izquierda del arroyo de las Villas, si bien los vestigios encontrados en los sondeos 25, 31 y 32 son un poco más tardíos, de época de Augusto y de mediados del siglo I d.C.; este vacío cronológico entre estas factorías es explicado por la falta de un mayor número de sondeos en la zona.

En la siguiente campaña arqueológica, llevada a cabo en 1967 y dirigida por G. Nicolini, se actuó de nuevo en el área monumental de la ciudad, principalmente en el foro y en el Capitolio, pero también se realizó un reconocimiento de los ejes urbanos, y se continuaron los sondeos estratigráficos en el área donde la anterior campaña había proporcionado los niveles más antiguos, realizándose una cata en la plaza del pueblo y otra en la llamada Calle del Mar (García y Bellido et alii 1968, 393-399; Domergue et alii 1974, 43-53). De estas actuaciones nos interesa ahora la información procedente del sondeo realizado en la playa (sondeo $24 \mathrm{CCV}$ ), dentro de las actuaciones dirigidas a conocer el trazado de los ejes urbanos. En esta cata, donde se esperaba encontrar el extremo del cardo, apareció una pileta, dividida por dos arcos ojivales alineados, pero la ausencia de datos estratigráficos válidos no permitieron fechar con precisión este conjunto (García y Bellido et alii 1968, 397; Domergue et alii 1974, 49-50).

Un nuevo estudio sobre la fábrica de salazones situada al oeste de la calle de las Columnas y en el extremo meridional del cardo, excavada casi por completo por París, fue realizado por Ponsich en 1976 (figura 2), quien plantea la dificultad de identificar este conjunto industrial como parte de la muralla sur de la ciudad, tal y como defendía el investigador francés autor de la propuesta (Ponsich 1976, 69-79).

Ponsich se basaba fundamentalmente en tres razones: primero, en la ausencia de paralelos semejantes en Occidente; segundo, porque resulta difícil considerar como muralla un muro de mampostería que no sobrepasa los $0,70 \mathrm{~m}$. de espesor, así como pensar que los cuatro vanos de la fachada sean saeteras antiguas construidas al revés y, por consiguiente inadaptadas a la defensa, pues lo normal es que sean estrechas al exterior y no al interior de la ciudad. Por todo ello defiende que se trata de una fachada con cuatro ventanas cuya forma es poco frecuente, pero concebidas para dar la mayor iluminación posible al interior de las salas de la fábrica de salazones. Opina que el interés de esta fachada reside en sus $4 \mathrm{~m}$. de altura que permite plantear la existencia de un piso alto destinado a secar el pescado o como almacén de ánforas vacías. Esta última hipótesis vendría avalada, según Ponsich, por el hallazgo de un amontonamiento de ánforas en la calle, delante de la puerta de acceso a la fábrica, que podría ser explicado como consecuencia de su caída desde el piso alto, al derrumbarse.

En cuanto a la planta y al funcionamiento de esta instalación considera que la sala 10 serviría para la recepción del pescado (figura 2), que sería introducido directamente en esta estancia desde la línea de playa, mientras que París opinaba que en esta sala se procedería al despiece y limpieza del pescado; a continuación, el pescado se depositaría en las salas 8 y 9, donde se le dejaría escurrir, antes de ser despiezado y cortado; proceso que tendría lugar en la sala 11, donde París situaba el almacén; por último, en el extremo de esta misma sala se sitúan las piletas para las salazones. 


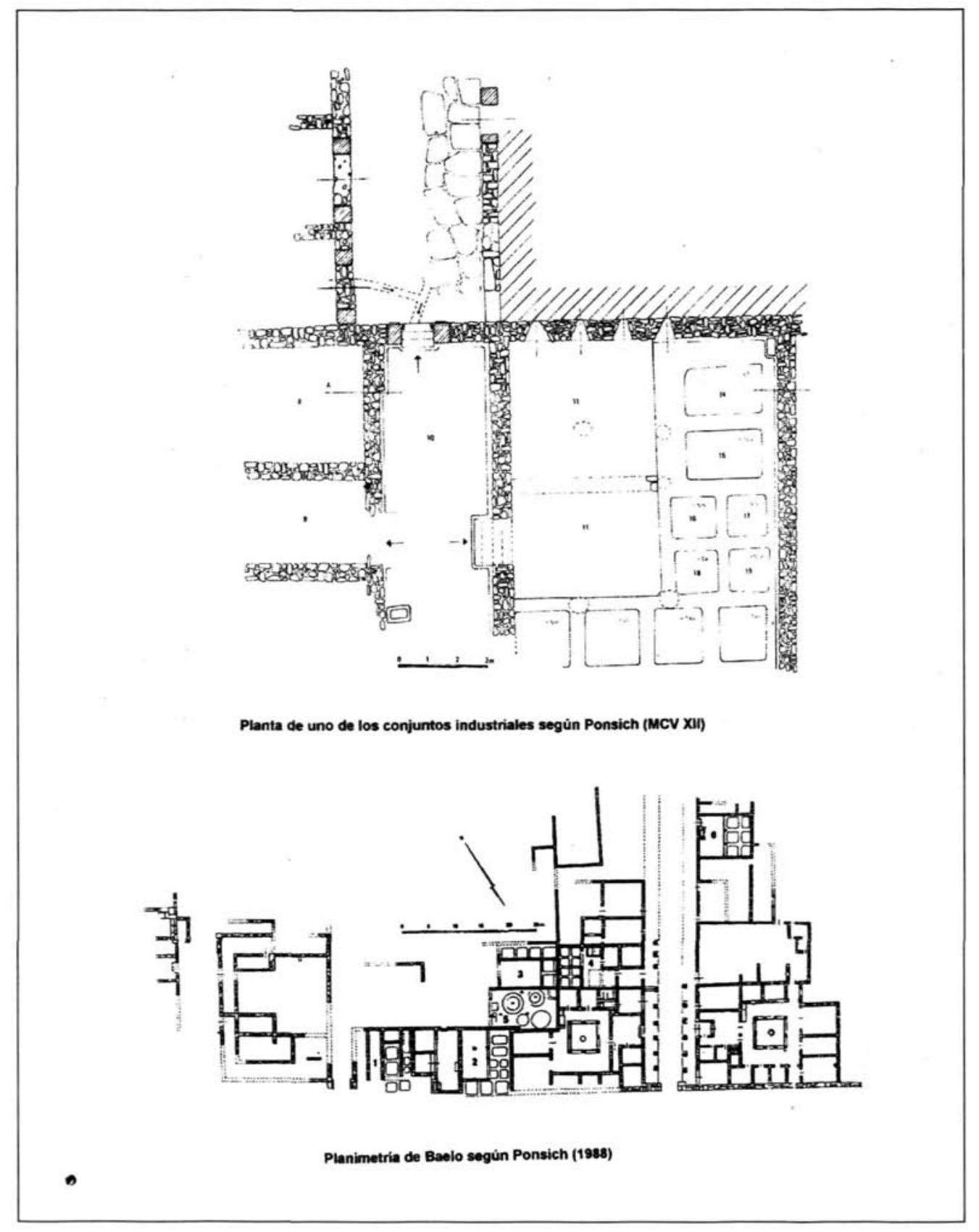

Figura 2. Plantas de la factoría Baelonense según $M$. Ponsich. A) Detalle del conjunto industrial más meridional (Ponsich 1976, 72). B) Planimetria general de la factoria (Ponsich 1988) 
Opina que la fabrica sufrió una modificación en la fachada exterior, según deduce de la adición de tres peldaños en la puerta de acceso que indicarían un levantamiento de $55 \mathrm{~cm}$. del umbral y de la parte exterior de la fábrica; al tiempo que fueron reparados los suelos del interior y se añadieron unas columnas en la sala 11 para sostener un tejado. El momento en que se realizaron tales modificaciones no lo especifica, tan sólo hace referencia al hallazgo en las piletas $n^{\circ} 14$ y 15 , que no habían sido totalmente vaciadas por el equipo de París, de fragmentos de sigillata clara D de las formas 38 y 54, así como sigillata clara estampillada, que le permiten defender que las piletas fueron colmatadas probablemente a principios del siglo $\mathrm{V}$.

Tendremos que esperar a la campaña arqueológica de 1979 dirigida por J.N. Bonneville para tener noticias de una nueva fábrica de salazones, hallazgo que se produjo al realizar un sondeo en una insula al borde del decumanus maximus (Dardaine y Bonneville 1980, 375-419). Se trata de una insula de uso industrial y comercial, construida en función de la fábrica de salazones que se sitúa justo en el centro de la misma (figura 3), además de notar cómo la disposición del local tuvo que adaptarse al plan urbanístico general que había establecido una alineación de tiendas a todo lo largo del decumanus maximus.

La insula está formada por cuatro salas rectangulares en sentido este-oeste (salas I-IV), completadas hacia el norte por otras cuatro pequeñas salas también rectangulares, en sentido este-oeste (salas V-VIII); todas ellas se organizan de dos en dos a ambos lados de una larga sala (sala IX-X), donde se encuentran de forma escalonada cuatro grandes cubetas destinadas a la producción de salazones de pescado y, a continuación otras tres pequeñas piletas reservadas para la elaboración de distintas variedades de garum. El área de preparación de pescado se situaría en las salas I y II, que presentan un suelo de mortero y dos pequeñas pilas para recoger el agua residual, pero además en la sala I se encuentra una gran piedra de molino que serviría para el trabajo de la sal y la salmuera; a continuación, en la sala IX-X se instalaron los saladeros, ya comentados. En cuanto a las salas VII y VIII, situadas al norte de la fábrica, parece que no están en relación con el funcionamiento de la factoría, al no existir comunicación entre estas dos habitaciones y las de la instalación industrial. Por último, las salas situadas al oeste de la fábrica corresponden a dos tiendas y sus respectivas trastiendas, sin que necesariamente estuvieran vinculadas con la fábrica. La creación de esta instalación data de la época de Claudio y Nerón, o sea del momento en que se llevó a cabo la renovación de la ciudad y, estuvo en funcionamiento alrededor de dos siglos, hasta mediados del siglo III d.C. aproximadamente. Durante cerca de 75 años, tierra y residuos diversos se fueron acumulando en el interior de las piletas y en el suelo de la primitiva fábrica, antes de que fuera nivelado hacia los años 350-360 para llevar a cabo una reestructuración completa del sector, al levantarse una casa tal vez con una tienda en el pórtico.

Durante los últimos años de los setenta y primeros de los ochenta se excavó el Macellum, los trabajos fueron llevados a cabo por F. Didierjean, C. Ney y J.L. Paillet. Estas investigaciones dieron lugar a una publicación monográfica del edificio dentro de la serie de publicaciones de la Casa de Velázquez destinada a Belo, en concreto el número III (Didierjean et alii 1986). 


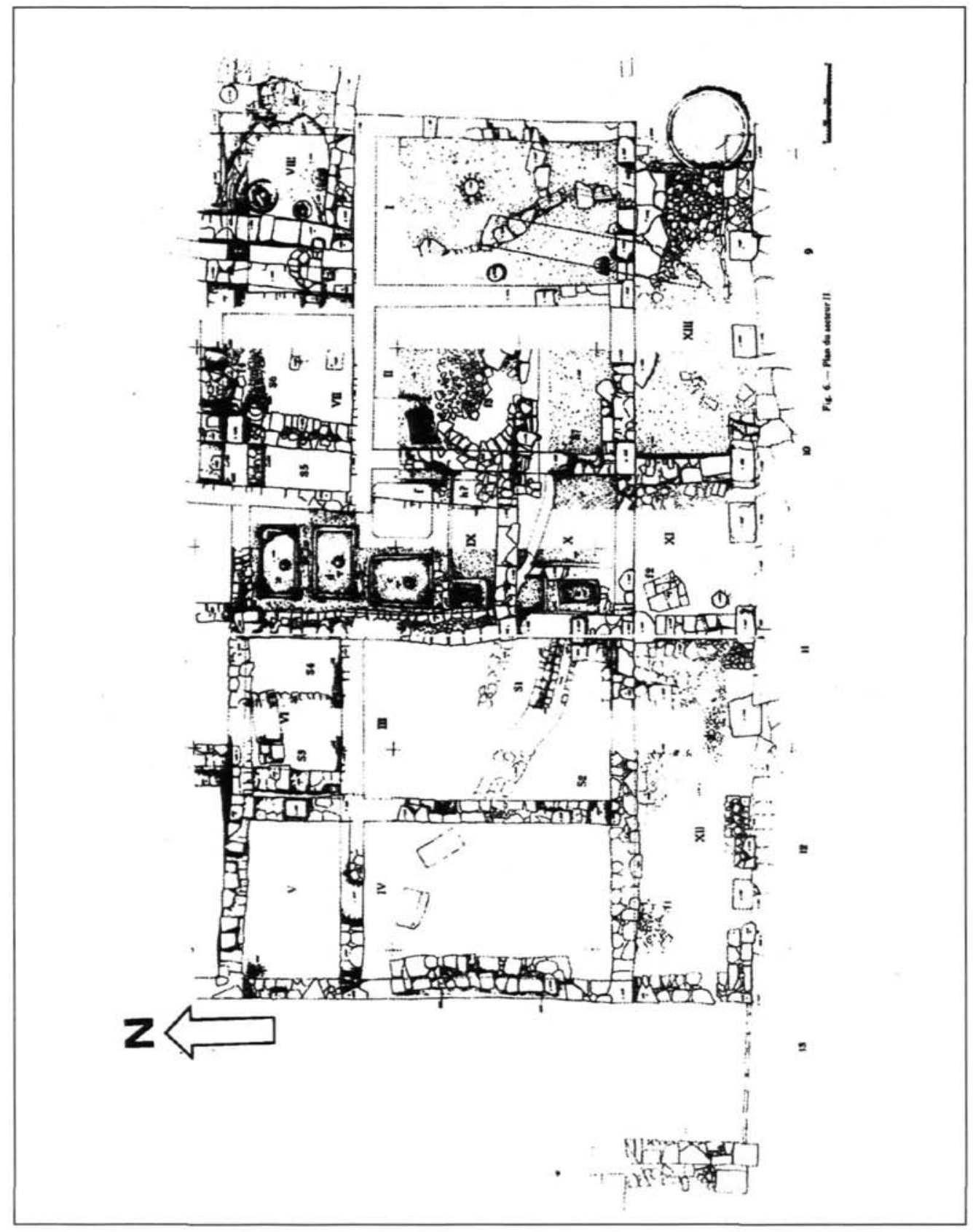

Figura 3. Estructuras industriales documentadas al norte del decumanus maximus, con las piletas revestidas de signinum en los denominados espacios IX y X (Dardaine y Bonneville 1980, fig. 6) 
Con motivo de los sondeos estratigráficos realizados para conocer las ocupaciones anteriores al Macellum se halló, durante la campaña de 1983, en el sondeo 33 efectuado en el espacio que sería ocupado por el pórtico oeste del Macellum, una pequeña pileta destinada a la elaboración del garum, datada en época de Nerón. Según sus excavadores, la presencia de esta pileta revela existencia de una actividad artesanal en el lugar, que debía ser marginal (Didierjean et alii 1986, 89).

También entre los años 1981 y 1983 M. Martín Bueno, con la colaboración en 1983 de J. Liz, llevó a cabo una serie de actividades arqueológicas encaminadas a recuperar el sector sur de la ciudad, concretamente el situado directamente sobre la playa, donde como hemos visto trabajaron P París y más puntualmente M. Ponsich (Martín Bueno et alii 1984, 487-496).

Tras una labor de limpieza y acondicionamiento para la documentación planimétrica y fotográfica de la Casa del Reloj y de la Casa del Oeste (figura 4), se llevó a cabo en 1983 un sondeo estratigráfico en la parte exterior del muro sur de cierre de dicha casa, con el fin de comprobar la estructura de la muralla sur de la ciudad en este sector (sondeo $\mathrm{CI}$ ) y, se observó que el muro descansaba sobre el lecho de arena de la misma playa, a $1 \mathrm{~m}$. por debajo del nivel del suelo de la habitación contigua, la $\mathrm{n}^{\circ} 30$, y que sólo existía un rebanco de fundación de $13 \mathrm{~cm}$. de ancho por $18 \mathrm{~cm}$. de alto. A esta altura se localizó dentro de un estrato de tierra compacta, el resto de un hogar con abundantes vértebras de atún y algún material cerámico. Un segundo sondeo se realizó en la Calle de las Columnas, al norte de la Casa del Reloj (sondeo CII), donde se obtuvo una secuencia estratigráfica que va desde poco antes del cambio de Era hasta finales del siglo IV.

En esta misma campaña se trabajó en varias cubetas de salazones de dos conjuntos industriales, que en algunos casos no habían sido descubiertas a principios de siglo y en otros no se habían terminado de excavar. Es el caso de la factoría situada al noroeste de la Casa del Oeste y cuyo acceso se realiza por el cardo (FI); de ella París había puesto al descubierto las piletas $n^{\circ} 69,70,71,72,81$ y 82, aunque no habían sido totalmente excavadas; allí se encontró una gran cantidad de material perteneciente a la techumbre de un edificio. La gran cantidad de tégulas e ímbrices encontrada, superior al que se produce cuando hay un desplome, le llevaron a considerar que hubo una reutilización antigua de la factoría con fines no industriales, de ahí que se rellenaran las piletas con material de derrumbe para dejar despejadas algunas salas. De esta misma factoría se excavaron cuatro piletas circulares de gran capacidad, pero no se aporta de ellas ningún dato específico. Asimismo, se excavaron total o parcialmente las piletas $n^{\circ} 74,75,76,77,78,79$ y 80 de la factoría situada al norte de la Casa del Oeste, cuyo acceso se realiza por la Calle de las Columnas (FII). En ellas se recuperaron terra sigillata clara, cerámicas tardías y en una de ellas, la $\mathrm{n}^{\circ} 79$, se halló un fuste de una columna, correspondiente a una basa que está situada en el punto en que se juntan los vértices de las pilas $n^{\circ} 74,76,77$ y 78 , cuyo capitel parece que había sido situado en el ángulo N-E de la cubeta 75. Este hallazgo permitió establecer la altura de los apoyos, que alcanzan $379 \mathrm{~cm}$.

Por último, nos queda hacer referencia a dos obras de carácter más general, una la realizada por Ponsich en 1988 dedicada en parte a las salazones de pescado y la otra, el trabajo de síntesis sobre la ciudad de Baelo Claudia publicada por Sillières en 1995. 


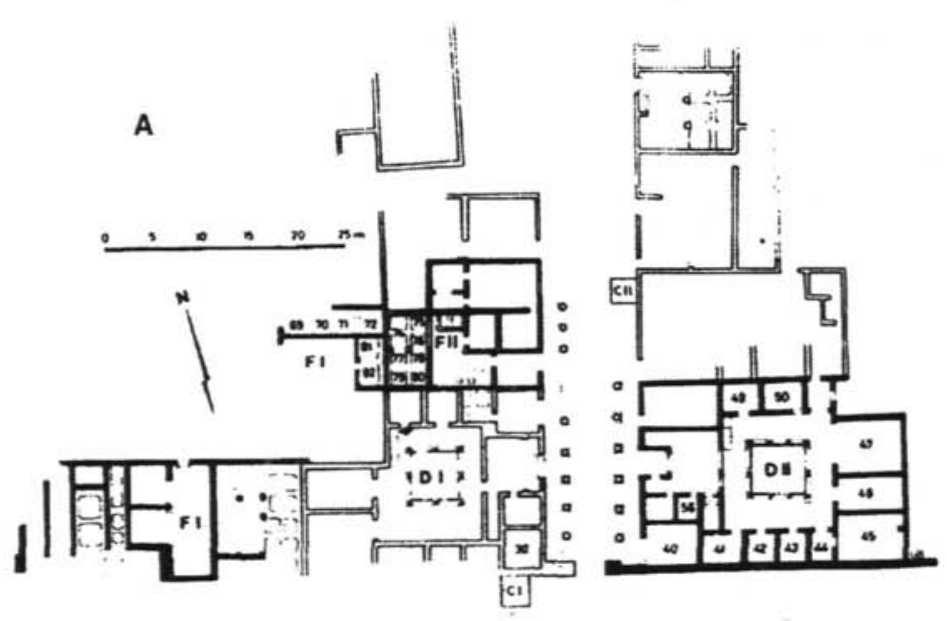

Planimetria de la factoría según Martín Bueno (1984)

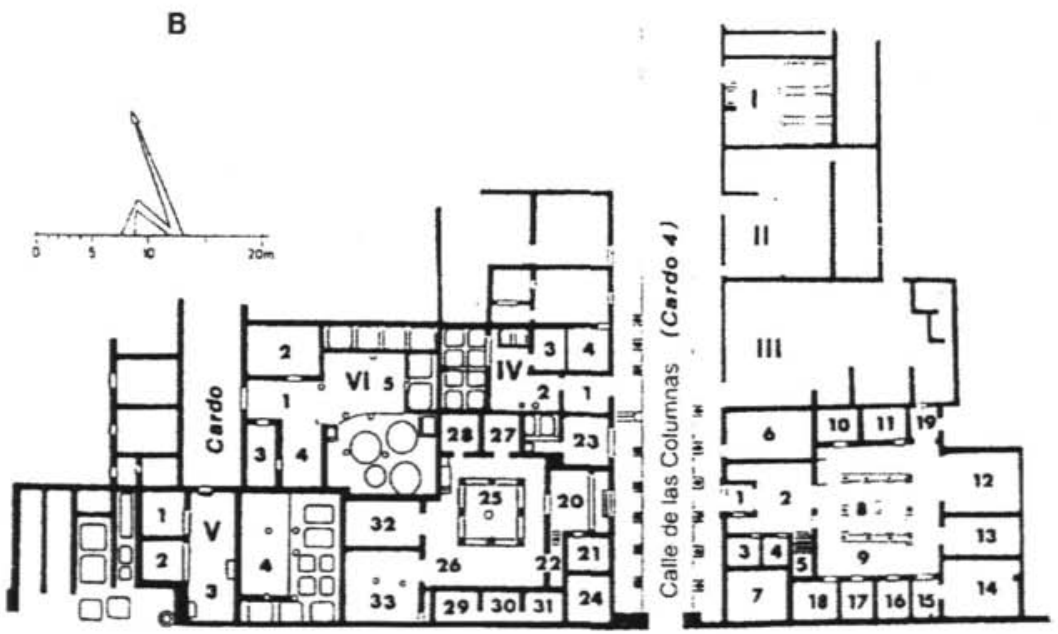

Planimetría de la factoría según P. Sillières (1995)

Figura 4. Planimetría de los conjuntos industriales de Baelo Claudia según M. Martín Bueno (1984, 496, fig. 4) y según P. Sillières $(1995,166)$ 
El trabajo de Ponsich tenía como objetivo prioritario el estudio de las distintas factorías de salazones aparecidas en la Bética y en la Tingitana, actualizando los datos ya citados de su primer trabajo monográfico sobre estas cuestiones realizado con una veintena de años de antelación (Ponsich y Tarradell 1965). Como es lógico, recoge el conjunto industrial de Baelo Claudia, si bien tan sólo hace referencia a las factorías situadas en el llamado barrio del puerto, que fueron excavadas por París, por él mismo y por el equipo dirigido por Martín Bueno y, de ellas, tan sólo realiza una somera descripción de seis conjuntos, destacando su emplazamiento y el número de piletas encontrado en cada uno de ellos ${ }^{[7]}$ (Ponsich 1988, 192-199). Considera que la factoría 1 tendría un acceso directo desde el mar, y que sólo presenta seis piletas; además interpreta como dos conjuntos diferentes el 3, con seis piletas, y el 5, del que advierte sobre la gran capacidad de las cubetas troncocónicas que servirían para trozos grandes de pescado y, tal vez, para salsamenta de ballena; de este conjunto aporta su cronología, con un inicio en época preclaudia o claudia y un uso hasta el siglo V o VI.

No menciona el resto de las piletas encontradas tanto dentro como fuera de la ciudad, aunque sí da a conocer la existencia de fondos de pilas de salazones, hechos en argamasa revestida de opus signinum, encontrados en la parte oeste de la bahía de Bolonia, en la vertiente oriental de cabo Camarinal; considera que se trataría de una factoría aislada, en funcionamiento durante el siglo IV d.C. por el material cerámico recogido (Ponsich 1988, 199). También cita la frecuente aparición de este tipo de piletas en la zona sudeste del cercano pueblo de El Lentiscal, al este de Bolonia (Ponsich 1988, 192).

En cuanto al estudio global de Sillières sobre la ciudad de Baelo Claudia se trata, como el propio autor señala en la introducción, de un resumen de los resultados de las excavaciones, así como de la historia de la ciudad y su territorivm. Un capítulo, el séptimo, está dedicado a los edificios privados: las casas y las fábricas de salazones; en él, tras hacer un breve comentario sobre las fábricas de conservas de pescado y las actuaciones arqueológicas llevadas a cabo, realiza un análisis bastante detallado de las diferentes instalaciones industriales (figura 4, infra), y además reelabora la planta del barrio de la calle de las Columnas, realizado por G. Bonsor, mediante el examen previo de los vestigios (Sillières 1995, 166, fig. 87), planteando el problema de la cronología de esta actividad en la ciudad. Comienza por las fábricas situadas al este y al oeste de la Caile de las Columnas, a las que atribuye una nueva numeración: conjuntos I al VI, que es la que adoptamos en este trabajo, como ya hemos comentado anteriormente.

El Conjunto I situado al este de la calle fue descrito por P. París, pero sus dimensiones son aportadas por primera vez. Una gran sala dividida en dos espacios de similar superficie, el primero de 7,40 por $4,30 \mathrm{~m}$. dedicado a la preparación y troceado del pescado, con una pequeña pileta $(1,35$ por 0,49 por $0,95 \mathrm{~m})$ para fabricar garum, no mencionando el banco descrito por París ubicado a la entrada de la sala; el segundo espacio de 7,40 por

[7] Este autor publica una planimetría de la factoría, que reproducimos en la figura 2, que es la misma publicada por él mismo conjuntamente con $\mathrm{M}$. Tarradell a mediados de los años sesenta, incluyendo únicamente los datos novedosos del C. V. 
4,60 m está constituido por los saladeros, con seis piletas de diferentes dimensiones: las mayores de $2 \mathrm{~m}$. de lado y entre 2,20 y $2,50 \mathrm{~m}$. de fondo y la menor de 2,10 por $1,60 \mathrm{~m}$ y $2,50 \mathrm{~m}$. de fondo. A continuación vienen los Conjuntos II y III, de los que no da ninguna descripción pues no han sido excavados. Al oeste de la Calle de las Columnas se encuentran los conjuntos IV, V y VI. El Conjunto IV de unos $80 \mathrm{~m}^{2}$ fue considerado por París como una tienda con sus almacenes, pero ya Martín Bueno, que excavó las piletas, defendió que se trataba de una factoría, aunque no definió la funcionalidad de cada una de las salas. Sillières la describe como una fábrica formada por una primera sala destinada a la recepción y preparación previa del pescado, una segunda sala para el descuartizamiento del pescado, con dos aljibes gemelos bajo el suelo, de $1,80 \mathrm{~m}$. de fondo, y con siete piletas al fondo, si bien en realidad se trata de ocho, como se puede advertir nítidamente en su plano; además de dos pilas más pequeñas para la elaboración del garum; por último, las salas 3 y 4 son consideradas almacenes.

El Conjunto V, situado al final del cardo, fue exhumado casi por completo por París y estudiado de nuevo por Ponsich, con quien Sillières está de acuerdo en considerar el muro, con puerta de acceso y cuatro vanos, como perteneciente a la fachada de la fábrica, y no como parte de la muralla sur de la ciudad, como defendió París. Sin embargo, discrepa con Ponsich sobre la existencia de un piso alto, pues argumenta que no queda ninguna huella del mismo en el muro que se conserva; en su opinión, las salas eran altas y no tenían techo, pero iban cubiertas por una buena techumbre. Advierte que se desconoce la extensión de este conjunto, porque toda la parte sudoeste no está bien determinada y considera que las pilas del oeste pertenecen a otra fábrica, aun así y teniendo en cuenta estos datos aporta sus medidas, $19 \mathrm{~m}$. de oeste a este y $11 \mathrm{~m}$. de sur a norte. En cuanto a la funcionalidad de cada una de las salas está de acuerdo con Ponsich en todas, salvo en las salas 1 y 2, que él considera que servirían para almacenar ánforas, mientras que Ponsich daba esta funcionalidad al piso alto y sugería que en estas salas se dejaría escurrir el pescado.

Del conjunto VI, Sillières aporta por primera vez las dimensiones de cada una de las dependencias, así como la distribución y funcionalidad de cada sala. La fábrica mide unos $250 \mathrm{~m}^{2}$, la puerta de acceso da a un pasillo $\left(\mathrm{n}^{\circ} 1\right)$ que comunica todo el edificio, el cual está dividido en dos partes: la mitad occidental (salas $n^{\circ} 1,2,3$ y 4) servía de almacén, de trastero o para alguna otra función, puede que los espacios 3 y 4 fueran patios o corrales, puesto que los vanos de la fábrica adyacente tomaban la luz por este lado. La mitad oriental era la fábrica (sala 5), con su área central para preparar y cortar el pescado, y alrededor de ella las pilas de salazones de muy diferentes tamaños, con capacidades que van desde los $5 \mathrm{~m}^{2}$ hasta los $15 \mathrm{~m}^{2}$; piensa que estas diferencias de capacidad se deben relacionar con las capturas de pescado, por lo que las mayores se llenarían coincidiendo con la temporada de paso de los atunes. En cuanto a la cubierta del edificio, ésta se soportaba por medio de columnas, cuyos primeros tambores siguen aún in situ.

Sillières (1995, 173-174) menciona que esta fábrica se vio afectada por una de las transformaciones a la que fue sometida la Casa del Oeste, que fue ampliada con las salas $\mathrm{n}^{\circ} 32$ y 33 ganando terreno a la parte sudeste de la fábrica de salazones. Advierte que en la sala 29 de la Casa del Oeste se puede ver la base de un muro derribado y en la galería occidental del peristilo, y que dicha base se encuentra exactamente en la prolongación del 
muro oeste de la habitación 28. Añade que en la sala 33 afloran al nivel del suelo los tambores de dos columnas, las cuales pertenecerían a la fábrica de salazones, en cuyas salas hay varias del mismo tipo. Por todo ello piensa que, en un principio, la Casa del Oeste acababa en el muro que se derribo, y que las dos grandes salas fueron añadidas posteriormente, ganando terreno a la fábrica. También examinó todos los muros de esta casa, así como de la Casa del Reloj, y distinguió la utilización de tres tipos de aparejos diferentes, al tiempo que estableció comparaciones con edificios de la ciudad cuya datación es segura; la aparición del tercer tipo de aparejo, caracterizado por incluir numerosas piedras de calcarenita mal escuadradas y por la abundancia de mortero, lo vincula con la transformación descrita y encuentra este mismo tipo de aparejo en el Macellum, edificio fechado en época de Trajano.

En lo que se refiere a las otras fábricas de salazones constatadas en la ciudad de Baelo Claudia, Sillières hace una breve exposición de la fábrica situada al este del Macellum y al borde del decumanus maximus, excavada por Bonneville, con el que está de acuerdo en la descripción de la planta y en la cronología; si bien plantea la posibilidad de que esta instalación fuera también un despacho de pescado salado y de garum, dado que las tres salas dan al pórtico del decumanus maximus. Plantea, igualmente, el problema de los inicios de esta actividad en la ciudad a través de los datos proporcionados por los sondeos efectuados en 1966 y 1967, y defiende que las primeras fábricas de salazones se construirían ya hacia finales del siglo II a.C.; algunas desaparecerían durante la primera mitad del siglo I a.C., cuando se hicieron las transformaciones urbanísticas, mientras que otras lo harían durante las reformas de mediados del siglo I d.C., siendo reemplazadas estas antiguas instalaciones por otras nuevas que se levantarían a lo largo del mismo siglo I d.C. Para la decadencia de esta actividad y el abandono de las fábricas utiliza la cronología proporcionada por la fábrica excavada en el decumanus maximus, que no funcionaba más allá del siglo III d.C. Y considera que las cronologías más tardías defendidas por Ponsich no se pueden mantener en la actualidad, al no haberse encontrado piletas de salazones en ningún estrato tardío de la ciudad, además del hecho contrastado arqueológicamente de la situación de los niveles de ocupación del Bajo Imperio a mucha mayor altura que las piletas de salazones; por ello piensa que el resurgimiento de Baelo en el Bajo Imperio no se debía a las industrias de conservas y salazones de pescado, ya que probablemente no existían en dicho momento.

Por último, trató el problema de la muralla sur (Sillières 1995, 73 y 80-81), indicando que no se ha podido encontrar ningún vestigio seguro. No está de acuerdo con París en considerar como muralla la pared sur de la Casa del Oeste y de la Casa del Reloj, ni tampoco que la puerta que daba hacia el mar se encontrara en el extremo méridional de la Calle de las Columnas, pues no existen huellas de las torres, que tendrían que flanquear la puerta a ambos lado de la calle y, porque la pared que París considera muralla, que mide escasamente $0,80 \mathrm{~m}$. de espesor, no presenta el aspecto de los tramos de fortificación conocidos.

En fechas más cercanas a nosotros, han sido realizados otros trabajos que plantean la especificidad de las factorías de Baelo Claudia en relación con la problemática general de las industrias conserveras hispanas, valorando la imprecisión cronológica que se deri- 
va de los estudios publicados hasta la fecha y la existencia de un conjunto industrial al norte del decumanvs, que es el que proporciona dataciones más fiables para valorar una posible interrupción temporal de las actividades industriales a mediados del s. II d.C. (Lagóstena 1999, 173 y 365; 2001). Debemos destacar especialmente en estos últimos estudios la acertada propuesta de un mantenimiento de las actividades industriales hasta al menos finales del s. V d.C., invalidando las propuestas crono-estratigráficas de Domergue derivadas éstas de una incorrecta valoración del registro cerámico (Lagóstena 1999, 175).

\section{ESTADO DE LA CUESTIÓN PREVIO}

Ya hemos planteado explícitamente cómo las factorías baelonenses aparecen citadas de manera sistemática como paradigma en Hispania y por extensión en todo el Mediteráneo occidental. Sin embargo, la problemática específica de sus cetariae es prácticamente desconocida a nivel de detalle, como veremos a continuación.

Los datos existentes previamente al inicio de nuestras investigaciones se resumen, concisamente, en lo siguiente. Desde las primeras excavaciones realizadas en la ciudad a finales del siglo XIX y durante los primeros años del s. XX se documenta la aparición continuada de piletas de salazón de pescado que confirmaban la vocación marinera de esta ciudad hispanorromana y su vinculación a las actividades pesqueras. De dichas actuaciones, incluyendo las primeras visitas de P. París a Bolonia, no se conservan testimonios más allá de las menciones aisladas de piletas o de balsas destinadas a la elaboración de conservas de pescado. El primer gran impulso en el conocimiento de la factoría, y al mismo tiempo el más importante hasta ahora, se debe precisamente a este investigador francés, el cual publica la primera planimetría del barrio meridional de la ciudad, la cual aparece firmada por $\mathrm{G}$. Bonsor, y que reproducimos en la figura 1. Se trata de una planimetría muy detallada que ha servido de base documental para todos los autores que han tratado el tema con posterioridad, básicamente M. Ponsich, M. Martín Bueno y P. Sillières, en la cual se presenta la planta completa de tres Unidades de Producción (que se corresponden con los Conjuntos Industriales I, IV y V) y una parte de la factoría que conocemos como C. VI. Este investigador procede, como hemos visto en el apartado precedente, a la descripción pormenorizada de los espacios atribuyendo un uso específico a las diversas estancias, propuestas que en buena parte no pueden ser mantenidas en la actualidad ante la ausencia de argumentos objetivos al respecto. Una propuesta planteada explícitamente por P. París fue considerar como muralla meridional de la ciudad una unidad constructiva situada al norte de sus habitaciones $\mathrm{n}^{\circ} 8,10$ y 11 , hipótesis con la que no coincidimos al constituir la misma únicamente el muro perimetral norte del Conjunto Industrial VI.

El pionero trabajo de M. Ponsich y M. Tarradell se tradujo en la publicación de la citada planimetría, procediendo sólo a la renumeración de los espacios industriales, definiendo tres grandes fábricas, las cuales coincidian, grosso modo, con las insulae en las cuales quedaban divididas las edificaciones por dos cardines paralelos (la denominada desde antiguo Calle de las Columnas y otro eje viario situado más al oeste), dentro de las cuales identificaban 5 conjuntos industriales. De ellas únicamente se procedió a la enumeración 
puntual de algunos detalles constructivos o funcionales de las estancias que las conformaban.

El siguiente gran impulso para el conocimiento de las salazones en Baelo Claudia debe ser atribuido a C. Domergue, investigador que confirmó el origen tardorepublicano de las industrias, entre finales del s. II o principios del s. I a.C., así como su continuidad durante época altoimperial, centrando su aparición en la orilla derecha del arroyo de las Viñas. Son fruto de sus investigaciones la propuesta del primer establecimiento humano en la zona como consecuencia de la explotación de las instalaciones industriales, así como un posible desplazamiento posterior de las actividades industriales a la orilla izquierda del arroyo, en coincidencia con el Barrio Industrial de la ciudad.

El trabajo de síntesis realizado por Ponsich en 1976 se centra en la interpretación funcional del Conjunto $\mathrm{V}$, indicando las reformas en el mismo y planteando una colmatación de algunas de sus piletas a principios del s. V. Rechaza la propuesta de considerar el muro perimetral norte de esta factoría como la muralla (=propuesta de P. París), por diversos motivos ya comentados anteriormente.

La excavación de parte de la insula al borde septentrional del decumanvs maximvs por Bonneville y Dardaine permitió aportar dos datos de fundamental interés para el estudio de las industrias conserveras baelonenses. Por un lado, la cronología, pues sus estructuras se mantuvieron en uso entre época claudio-neroniana y mediados del s. III d.C. Por otro lado, documentada una factoría, tal y como fue interpretado por estos investigadores, al norte del citado eje viario. En esta misma última línea debemos situar el hallazgo de una pequeña pileta de salazón documentada en el macellvm de la plaza del foro.

Las intervenciones realizadas a principios de los años ochenta por el equipo de $\mathrm{M}$. Martín Bueno permitieron completar la planta del C. VI, al tiempo que se propuso en dicha zona la reutilización en un momento determinado de las industrias con fines no estrictamente industriales. Se terminaron de excavar los saladeros localizados en la parte posterior del C. IV y se realizaron dos sondeos estratigráficos, de los cuales el localizado ante el frontal del C. III permitió detectar una estratigrafía que comenzaba poco antes del cambio de Era y culminaba a finales del s. IV d.C. Serían estas las últimas excavaciones sistemáticas realizadas en la factoría de salazones hasta la fecha.

El trabajo de síntesis realizado por $\mathrm{M}$. Ponsich a finales de los años ochenta aportó pocas novedades al respecto, añadiendo a la planta las estructuras exhumadas por $\mathrm{M}$. Martín Bueno, renumerando las factorías (añadiendo un conjunto más a los cinco ya existentes), y proponiendo como hipótesis novedosa el procesado de cetáceos en las conocidas piletas circulares de sección troncocónica. Alude a la existencia de una pequeña cetaria en Camarinal, que fecha en el s. IV d.C. así como piletas aisladas al SE del núcleo de población de El Lentiscal.

Ha sido Sillières el último investigador que ha tratado monográficamente el estudio integral de la factoría, renumerando las mismas de este a oeste y de norte a sur, con VI conjuntos que son los que mantenemos en la actualidad, de dos de los cuales presenta una descripción detallada, que le sirven para plantear su división interna de las industrias en "petites et grandes conserveries" (C. I y C. VI respectivamente). Aporta el estudio métrico 
detallado de las industrias citadas y coincide con Ponsich en no considerar la fachada norte del C. V con la muralla de la ciudad. Es muy útil su propuesta de análisis constructivo de las domvs, planteando analogías cronológicas con otros edificios de la ciudad que presentan similares técnicas edilicias. Respecto a la cronología, revisa los testimonios existentes situando su origen en el s. II a.C. y su declive en el s. III d.C., aceptando la cronología final de la factoría excavada al norte del decumanvs (interpretando este último conjunto como un despacho de pescado salado y garvm más que con una factoría propiamente dicha).

Por último, recordar los recientes trabajos de L. Lagóstena, que han puesto su punto de mira fundamental en la valoración de la continuidad cronológica de las factorías baelonenses en la Tardía Romanidad, retomando las antiguas propuestas de M. Ponsich y M. Tarradell completamente olvidadas $-\mathrm{O}$ invalidadas- en otros trabajos recientes ya citados.

Podemos resumir en una serie de puntos las principales cuestiones derivadas de los estudios realizados durante ya más de un centenar de años en las factorías de salazón de Bolonia.

- Delimitación física: concentración de las piletas en la parte baja de la ciudad, tanto a la derecha como a la izquierda del curso del arroyo de las Villas, siendo esta última parte la que concentró el desarrollo industrial de estas actividades. Adicionalmente, puntual presencia de piletas en la zona de necrópolis, en el macellvm y al norte del decumanvs maximvs. Alejados del barrio industrial se localiza la cetaria de Punta Camarinal y las piletas del Lentiscal.

- Relación factoría-ciudad: algunos autores citan la existencia de la muralla meridional al norte del C. V, si bien esta propuesta no es aceptada por la mayor parte de autores posteriores. Implícitamente existe una "resistencia" tácita a considerar las factorías del Barrio Industrial como localizadas intramuros.

- Planimetría y división interna del espacio: propuestas no consensuadas entre los diversos investigadores, plasmadas en la diversidad de unidades de producción definidas y las numeraciones no coincidentes. División interna de las estancias con usos funcionales claramente contradictorios según los diversos autores.

- Cronología: el inicio de las actividades planteado por Domergue a finales s. II o p. s. I a.C. no ha sido cuestionado con posterioridad. Se defiende más o menos abiertamente un floruit de las actividades industriales durante el s. I a.C. y el s. I d.C., con una continuidad hasta mediados del s. III d.C. Para algunos autores a partir de estas fechas ya no funcionan las actividades industriales (P. Sillières), propuesta que choca frontalmente con las menciones a colmataciones de las piletas en momentos centrados en el $\mathrm{s}$. $\mathrm{V}$ o incluso en el s. VI d.C. (M. Ponsich y M. Tarradell, M. Martín Bueno). Actualmente se documenta una apuesta manifiesta por el mantenimiento de las cetariae hasta la Antigüedad Tardía (L. Lagóstena).

- Interpretación errónea de las piletas revestidas de signinvm. Cualquier hallazgo en las excavaciones de estructuras revestidas con hormigón hidráulico han sido sistemáticamente relacionado con piletas de salazón de pescado. El caso más evidentes es el de la factoría definida al norte del decumanvs maximus por Bonneville y Dardaine, propuesta acep- 
tada posteriormente por P. Sillières o L. Lagóstena, si bien a nuestro juicio constituye una insula con tabernae cuyos espacios internos no se corresponden con instalaciones industriales relacionables con una cetaria.

\section{NUEVAS PERSPECTIVAS DE INVESTIGACIÓN}

Como se ha comentado al inicio de este estudio, los trabajos de documentación arqueológica de la factoría realizados durante el verano del año 2000 han permitido la obtención de una serie de datos inéditos sobre el conjunto industrial de Baelo Claudia que permiten plantear novedades en la investigación. Novedades que afectan al yacimiento en un doble sentido. Por un lado, se ha procedido a evaluar las propuestas de trabajo de los autores que han tratado esta cuestión previamente a nosotros, tratando de generar un estado de la cuestión sobre el que cimentar los conocimientos reales que tenemos hoy en día del barrio industrial de esta ciudad hispanorromana. Por otra parte, se ha obtenido documentación arqueológica de primera mano con la cual es posible avanzar en algunas de las hipótesis propuestas, decantándonos en una línea interpretativa específica, como veremos a continuación a título particular. Se ha optado por presentar en estas páginas los primeros resultados de la interpretación general de la factoría de Baelo Claudia, pasando de una escala macroespacial, al análisis de los diversos elementos constitutivos del objeto del sector de la ciudad objeto de estudio. De ahí que la primera cuestión necesaria para nuestro trabajo es la presentación de una planimetría actualizada en la cual integrar los diferentes elementos urbanísticos que conforman el espacio del barrio portuario de Baelo. Los problemas de investigación más específicos son abordados en el punto 4.3, en el cual se recurre a la casuística concreta de los denominados Conjuntos I y IV para plantear las propuestas de trabajo que, hoy por hoy, consideramos más adecuadas con la realidad física del Conjunto Arqueológico.

\subsection{Problemática urbanística y planimetría de la factoria baelonense}

Una primera cuestión que consideramos conveniente aclarar, previamente al estudio propiamente dicho de la factoría de salazones en sí misma, es la definición de la relación urbana existente entre factoría y ciudad. Desde los primeros trabajos realizados por los franceses en Baelo a principios de siglo, al menos una cuestión era evidente: la zona meridional de la ciudad tal y como se conservaba ésta en la actualidad estuvo destinada en la Antigüedad a usos industriales de carácter eminentemente pesquero. Esta cuestión, multiplicada exponencialmente por la entidad y extensión de los restos, inducía a considerar a los investigadores la existencia en este lugar de una parte significativa de la ciudad hispanorromana con una cierta entidad propia. Es por ello que P. París bautizó a esta zona como el "quartier industriel" (París et alii 1923, 169), denominación que se ha mantenido de manera más o menos explícita en la investigación posterior, frente a otras que han calado menos en la bibliografía como la de "barrio portuario" (Sillières 1995, 179). La cuestión más problemática no es otra que la consideración de la factoría de Baelo Claudia en relación con las diferentes partes del trazado urbano, tratando de solventar si la factoría se situaba 
intra moenia o fuera de las murallas de este municipio romano. La propuesta tradicional sería considerar a las factorías de salazón fuera del perímetro murario de la ciudad, como correspondería al urbanismo vitrubiano y, por tanto, canónico, apelando adicionalmente a los ejemplos conocidos de ciudades en el mundo romano en las cuales los "barrios industriales" siempre se situaban fuera del pomerium cívico. Las leyes municipales y la consuetudo edilicia romana parecían argumentos sólidos para sustentar esta propuesta. Veremos a continuación el planteamiento general de los diversos investigadores y nuestra propuesta, que adelantamos diverge respecto a la interpretación tradicional.

Ya P. París trató de solucionar este problema, advirtiendo la existencia de una unidad muraria a la cual se adosaban algunas de las habitaciones por él excavadas en el C.V, caracterizada ésta por estar "percée d'une série de meurtrières antiques, avec ébrasement extérieur, et placées tout près du sommet actuel. Cela prouve qu'il régnait un chemin de ronde à l'intérieur- (París et alii 1923, 178). Esta estructura, situada al norte de las estancias $\mathrm{n}^{\circ} 2,7,8,11$ y 14 de la planimetría publicada por este investigador, cuya descripción indica que tiene que ser por obligación coincidente con el muro perimetral norte del denominado Conjunto V, es la interpretada como la muralla del conjunto, por lo que la mayor parte del barrio industrial se situaría intra-muros, y únicamente algunas estructuras industriales se ubicarían fuera del perímetro murario. Esta propuesta no ha sido tratada en fechas posteriores de manera exhaustiva, a excepción de los trabajos de M. Ponsich (1976) y P. Sillières, los cuales planteaban su disconformidad con la identificación de la muralla meridional de la ciudad por parte de P. París con el citado muro perimetral del C. V, al tiempo que el último investigador citado tampoco aceptaba la propuesta de P. París de considerar como puerta meridional de la ciudad el extremo sur de la Calle de las Columnas. Los argumentos esgrimidos por estos investigadores para rechazar dicha propuesta eran por un lado la inexistencia de torres flanqueando dicho acceso meridional, y, sobre todo, el escaso espesor del citado muro meridional de cierre de las domus $(80 \mathrm{cms}$. circa) y sus diferencias respecto al recinto murario de la ciudad bien conocido en la parte restante de su trazado; estas cuestiones llevaron a Sillières a considerar que bien el frontal meridional de la muralla de Baelo presentaba una técnica constructiva diferente o bien que el trazado de la muralla era otro respecto al propuesto por P. París (Sillières 1995, 80-81).

Por el contrario, en la bibliografía especializada la factoría de Baelo Claudia es considerada como un unicum al integrar la factoría de salazones dentro del perímetro urbano, con un único paralelo conocido en el Mar Negro, concretamente las factorías de Tyritake (Curtis 1991, 52-53) ${ }^{[8]}$, si bien estas factorías cercanas a Panticapaeum son de menor entidad y extensión más reducida respecto a las baelonenses.

Nuestra propuesta es considerar de manera explícita que el Barrio Industrial de la parte meridional de la ciudad de Baelo Claudia, en el cual se encuentra instalada la factoría, fue planificado urbanísticamente dentro del perímetro murario de la ciudad. Los argumentos disponibles que permiten considerar la factoría de salazones intra muros son los siguientes.

[8] Este autor incide sobre las prescripciones legales que obligan a instalar las factorias fuera del perímetro urbano y a cierta distancia de este, según la documentación de época bizantina (Curtis 1991, 189). 

dad.

- Trazado de la cinta muraria oriental y occidental en la parte meridional de la ciu-

Conocemos parcialmente la trayectoria de la muralla al sur del decumanvs maximvs, si bien hoy en día es posible advertir que la torre situada al sur de la Puerta de Carteia en el tramo oriental de la muralla coincide prácticamente de manera lineal con la aparición de los primeros testimonios de la factoría, caso del Conjunto Industrial I. Sucede un fenómeno análogo con la denominada T34 y la continuación del tramo de muralla que parte de ella paralelamente a la margen izquierda del arroyo de las Viñas (Sillières 1995, plano). Las recientes excavaciones realizadas por el Conjunto Arqueológico han localizado restos de la cinta muraria occidental en puntos situados más al sur de algunos conjunto industriales, como veremos a continuación, confirmando esta tendencia' ${ }^{[!]}$.

- Existencia de una muralla "de prestigio” en el límite sur del yacimiento.

A continuación plantearemos la problemática del cierre de la cinta muraria por el sur del yacimiento según las propuestas de los diversos investigadores. A nuestro juicio el tramo meridional de la muralla baelonense coincide con la trayectoria del muro perimetral sur de la Casa del Cuadrante, continuando hacia el oeste en el muro de cierre sur de la Casa del Oeste y en la estructura que delimita por el sur el C. V (figuras 4 y 5). Dos factores contribuyen a dotar de contundencia a esta propuesta: la notable ortogonalidad de esta estructura, que presenta un trazado rectilíneo en un percurso superior a los 100 metros y, por otra parte, la escasa entidad de las estructuras arqueológicas al sur de dicha construcción perimetral ${ }^{110]}$. Evidentemente, se trata de una muralla de prestigio, como corresponde a una época posterior a la pacificación de Hispania en la cual estos elementos definitorios del pomerium urbano tienen esta función y no otra ${ }^{[11]}$. Es por ello que la escasa anchura de la unidad muraria en la zona sur (unos $80 \mathrm{cms}$.) no constituye a nuestro juicio un impedimento para considerarla como la muralla de la ciudad, si además tenemos en cuenta la existencia de análogas anchuras, cercanas al metro de espesor, en otros puntos del trazado murario de Baelo Claudia.

- Coincidencias urbanísticas en la parte meridional de la ciudad:

Consideramos que la continuidad del trazado de los ejes viarios al norte y al sur del decumanvs maximvs constituye una prueba evidente de cómo el Barrio Industrial estaba integrado perfectamente dentro de la trama urbana. Asimismo, resulta significativa la divi-

[9] Los datos gentilmente proporcionados por D. F. Alarcón, técnico-arqueólogo del Conjunto Arqueológico se sitúan en esta línea, y se pueden corroborar sobre el terreno en la actualidad, al haberse mantenido las estructuras sin cubrición.

[10] Agradecemos a D. C. Alonso Villalobos, del Centro de Arqueología Subacuática del I.A.P.H. de la Junta de Andalucía habernos facilitado los datos de las intervenciones realizadas en la playa de Bolonia en los últimos años, que han deparado hallazgos de algunas estructuras al sur del muro perimetral de las domus, si bien siempre de manera aislada y limitándose a hallazgos puntuales.

[11] En las diversas contribuciones al Seminario Stadtbild und Ideologie (DAI, Madrid.1978), cuyas actas están editadas por P. Zanker y W. Trillmich, se profundiza de manera pormenorizada en esta problemática. 


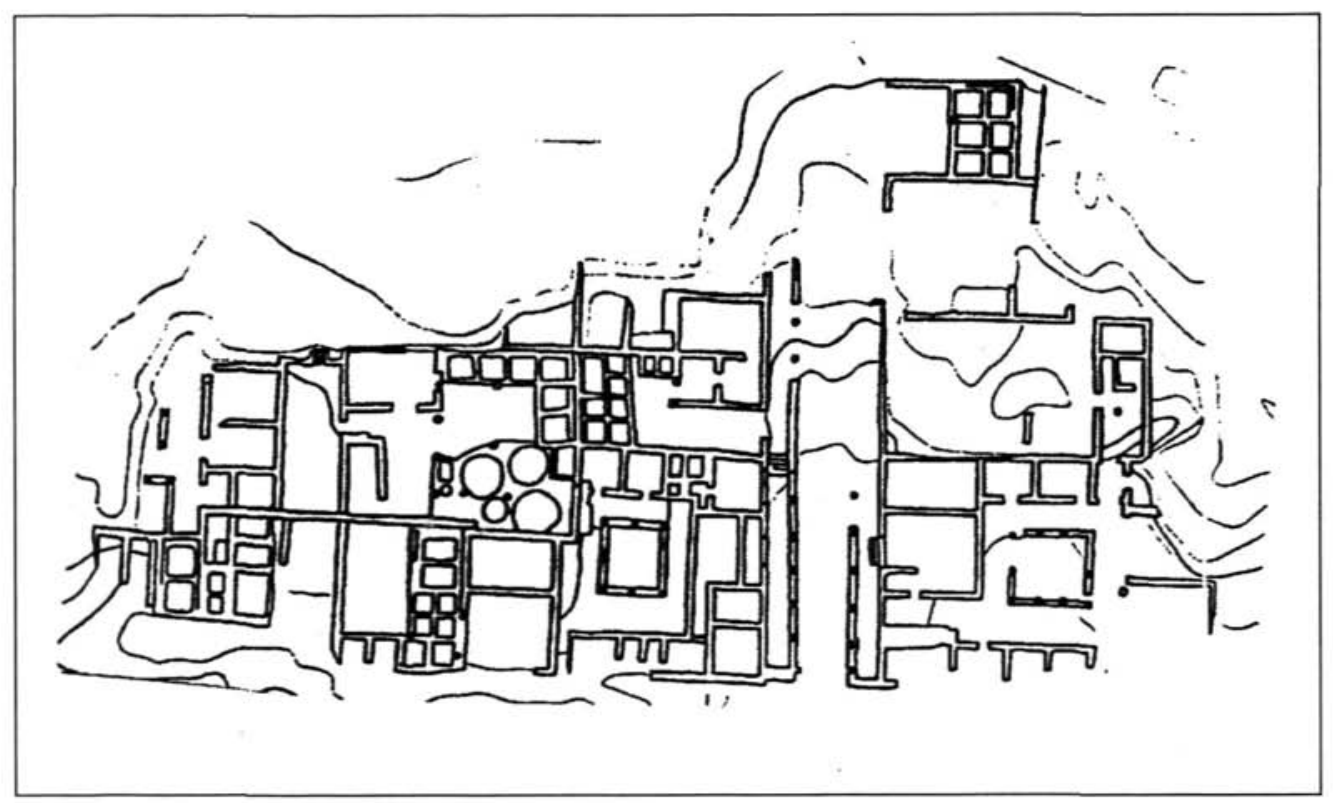

Figura 5. Planimetría de la factoria de Baelo Claudia, procedente de la cartografia informatizada del Conjunto Arqueológico (Consejería de Cultura de la Junta de Andalucía)

soria longitudinal materializada en la trayectoria del propio decumanvs maximvs, que preludia una nítida división interna de la ciudad y su articulación en barrios e insulae.

Diversos son los investigadores que han intervenido de manera más o menos directa sobre la factoría de salazón, si bien no contamos en todas las ocasiones con documentación detallada de las estructuras exhumadas por cada uno de ellos, como se ha podido comprobar en el apartado dedicado a la historiografía. Es por ello que de la totalidad de la factoría contamos en la actualidad con al menos cuatro planimetrías detalladas, publicadas respectivamente por P. París (1923, pl. I), M. Martín Bueno, M. Ponsich y P. Sillières, las cuales reproducimos en las figuras 1, 2B y 4 de este trabajo. A ellas le debemos sumar la cartografía informatizada de la totalidad del yacimiento realizada a mediados de los años noventa por el Conjunto Arqueológico ${ }^{[12]}$, cuya zona correspondiente con la factoría presentamos en la figura 5, y que es la que hemos utilizado durante el trabajo de campo.

Un primer elemento destacable es la disfunción existente entre las planimetrías publicadas, fruto básicamente de su realización en diferentes momentos, distantes varias décadas entre sí: más de sesenta años entre la de P. París y la de M. Martín Bueno, un lustro

[12] Agradecemos profundamente a D. A. Álvarez Rojas, director del Conjunto Arqueológico, permitirnos el acceso y uso de esta información, así como al técnico-arqueólogo del yacimiento, D. F. Alarcón, su inestimable ayuda y útiles sugerencias durante la realización del presente trabajo. 
entre la de este último investigador y M. Ponsich y una década aproximadamente hasta la planimetría más actualizada, realizada por P. Sillières. La más completa de todas es la más antigua (P. París, 1918), especialmente en lo referente a las estructuras situadas en la parte suroccidental del C.V, más concretamente al oeste del denominado espacio $\mathrm{n}^{\circ} 1$ por P. París, las cuales serán citadas con posterioridad únicamente por M. Ponsich, investigador que reproduce los espacios identificados en 1918 con tenues modificaciones. Las excavaciones realizadas a mediados de los años ochenta permitieron completar el espacio situado al norte de la habitación $\mathrm{n}^{\circ} 21$ definida por P. París, integrando en esta zona el bien conocido conjunto de piletas troncocónicas que aparecerá reflejado gráficamente desde entonces (Ponsich 1988, 194, $\mathrm{n}^{\circ}$ 5; Sillières 1995,166 , fig. 89). Toda esta zona en torno a la unidad de producción caracterizada por las "piletas troncocónicas" no aparecerá completada planimétricamente en sus límites norte y oeste hasta la publicación del estudio de P. Sillières $\left(1995,166, \mathrm{VI}, \mathrm{n}^{\circ} 1-4\right)$. Para evitar ser muy prolijos en la exposición, vamos a resumir este aspecto valorando cómo la planimetría de la factoría baelonense ha ido completándose de manera sucesiva como consecuencia de la realización de excavaciones arqueológicas con el paso de los años, habiendo utilizado los diversos investigadores la planimetría publicada por P. París -realizada en realidad por G. Bonsor, tal y como recuerda su rúbrica a pie de página- como base cartográfica de trabajo. Al mismo tiempo, incidir en el hecho manifiesto de que una parte de las estructuras exhumadas por P. París, especialmente aquellas situadas en la zona occidental del área excavada, no ha sido reflejada en las planimetrías más recientes, cuestión que tampoco ha sido posible abordar recientemente al encontrarse en la actualidad totalmente cubiertas por arena de playa y por vegetación.

\subsection{Definición de unidades funcionales}

Si a nivel urbanístico la concepción integral de la factoría presenta pocos problemas interpretativos a excepción de los detalles comentados en el apartado anterior, la articulación interna de los diversos espacios de uso industrial sí plantea una hermenéutica más compleja, por cuanto las diferentes propuestas publicadas son claramente divergentes entre sí.

Sí queremos aclarar desde un principio que la definición de áreas funcionales dentro de la factoría baelonense se limita a la interpretación de los restos arquitectónicos actualmente visibles, los cuales presentan testimonios evidentes de profundas remodelaciones internas, como veremos en el punto 4.3. Es por ello que nuestra propuesta se limita a la definición de "unidades de producción" atendiendo al análisis exhaustivo de los restos de la factoría baelonense llegados a nuestros días.

Otra premisa de partida que resulta conveniente aclarar es que el barrio industrial de Baelo no constituye una única instalación industrial homogénea y unitaria en el tiempo, como sí conocemos en el caso de otras instalaciones industriales, siendo la de Cotta cerca de Tánger (Ponsich 1988, 153) o la de Septem Fratres en la vecina orilla africana del Estrecho (Bernal y Pérez 1999, 28-51) las más ilustrativas de dicho modelo. Esta visión general, aceptada tácitamente por todos los investigadores que han tratado esta cuestión, lleva 
habitualmente a hablar de diversas "factorías de salazón" en la ciudad, entendiendo por cada una de ellas un conjunto industrial o unidad de producción autónoma. En el estado actual de nuestras investigaciones, la propuesta terminológica que parece más viable es la siguiente. Por un lado, ya hemos comentado que existen restos de factorías de salazones en diversos puntos de la ciudad: al sur del decumanus maximus, en diversos puntos al norte de dicho eje viario, en la orilla derecha del río de las Viñas, en el Lentiscal y, por último, en Punta Camarinal. Nosotros nos referiremos únicamente aquí a los restos de la factoría situados en la parte meridional de la ciudad y en la margen izquierda del arroyo, utilizando como punto de inflexión el citado decumanus maximus. Los diversos hallazgos de piletas en la zona del macellum o al norte de esta vía no parecen relacionarse con establecimientos industriales de producción de salazón -que no tal vez de venta- por lo que no son considerados aquí. Las piletas aparecidas en los sondeos realizados por Domergue en la 'parte derecha de la desembocadura del río, así como las citas de P. París sobre hallazgos similares en la necrópolis restan, por el momento, inciertos: probablemente se correspondan con factorías autónomas previamente a la reorganización física del barrio industrial de la ciudad. La factoría de Punta Camarinal es, a todas luces, una unidad de producción autónoma, probablemente bajoimperial, y cuya problemática se aleja de la de la factoría propiamente dicha, al menos en el terreno urbanístico. Pensamos que la propuesta más viable por el momento es considerar toda la zona al sur del decumanus como BARRIO INDUSTRIAL, mejor que barrio portuario o barrio pesquero, al ser las actividades productivas más que caracterizan esta zona de la ciudad, y además, al constituir la primera propuesta terminológica planteada para el mismo por los excavadores de la ciudad en la segunda década del s. XX. Dentro de dicho barrio industrial se localizan una serie de conjuntos industriales autónomos o factorías de salazón independientes, cuyo análisis pasamos a realizar a continuación.

P. París procede a la enumeración e interpretación funcional de las diversas habitaciones aparecidas en el barrio industrial, sin llegar a realizar una propuesta de interpretación integral para todo el conjunto. Sí deja claro, por otro lado, la existencia de dos domus señoriales en esta zona, cuyo tratamiento monográfico desarrolla en el capítulo VIII de su monografía (París et alii 1923, 119-168), y que hoy, conocidas aún como la Casa del Cuadrante y la Casa del Oeste, están perfectamente integradas en el urbanismo del barrio, como veremos detalladamente más adelante. Ponsich y Tarradell definen cinco factorías; por su parte, M. Martín Bueno únicamente realiza una numeración exhaustiva de aquellas zonas en las cuales interviene arqueológicamente, denominando Factoría II a la situada al norte de la Casa del Oeste, y que presenta fachada hacia la Calle de las Columnas y Factoría I a la situada a espaldas de ésta, hacia el oeste (Martín Bueno et alii 1984). Por su parte, M. Ponsich presenta a finales de los ochenta una reorganización numérica de las unidades productivas, definiendo seis conjuntos industriales en dirección oeste-este, como se puede apreciar en la figura 2, por los que añade una factoría más a las ya existentes, cambiando la numeración de los conjuntos 5 y 6 respecto a la propuesta publicada por él mismo una veintena de años antes. La última propuesta y más reciente es la de P. Sillières, que procede a la renumeración de las factorías, en este caso en dirección este-oeste (figura 4, infra), siendo esta última la propuesta más consensuada por la investigación reciente, y la que hemos adoptado inicialmente para el trabajo de campo. Como ya hemos comentado, todos 
los autores coinciden en la identificación de los espacios situados al sur de la Calle de las Columnas como sendas domus gemelas.

En la siguiente tabla se advierten las coincidencias numéricas entre las propuestas de los diversos investigadores

\begin{tabular}{|l|c|c|c|c|c|c|}
\hline AUTOR & \multicolumn{5}{|c|}{ CONJUNTOS INDUSTRIALES/ NUMERACIÓN DE ESTANCIAS } \\
\hline P. Sillières (1995) & I & II & III & IV & V & VI \\
\hline M. Ponsich (1988) & 6 & - & - & 4 & 1 y 2 & 3 y 5 \\
\hline M. Martín Bueno (1984) & & & & II & & I \\
\hline $\begin{array}{l}\text { M. Ponsich } \\
\text { M. Tarradell (1965) }\end{array}$ & 5 & & & 4 & 1 y 2 & 3 \\
\hline P. París (1923) & No 59 a 65 & - & - & N 35 a 37 & N $^{\circ} 1$ a 20 & - \\
\hline
\end{tabular}

A raíz de la redefinición de espacios por parte de los diversos autores son diversas las consideraciones útiles desde un punto de vista funcional. Por un lado, el total acuerdo de interpretación en relación con los espacios situados al este de la Calle de las Columnas. En segundo lugar la "autonomía" de la factoría con fachada a la zona occidental de la Calle de las Columnas (= C. IV), claramente definida como tal ab origine. Es también evidente la complejidad arquitectónica de los espacios situados en la parte central del barrio industrial, pues se definen bien dos espacios (factorías V y VI de Sillières) o cuatro (factorías 1, 2, 3 y 5 de Ponsich). Por último, resulta de fundamental interés para la investigación la zona situada al oeste del cardo definido por M. Ponsich y M. Tarradell en $1965^{[13]}$, que ha sido sistemáticamente olvidada en las propuestas de parcelación interna del barrio industrial.

Con estos datos de partida, y tras un análisis preciso de los testimonios arquitectónicos conservados actualmente en la zona meridional del Conjunto Arqueológico, la propuesta de definición espacial y división interna del barrio industrial que presentamos es la siguiente.

\subsubsection{El perímetro del Barrio Industrial.}

La extensión total del barrio industrial de Baelo Claudia parecen coincidir, al menos a tenor de la documentación disponible en la actualidad, con una superficie dedicada por completo a cuestiones industriales. Es decir, la totalidad de restos arqueológicos aparecidos en toda la zona baja se relaciona con factorías de salazones o con estructuras vinculadas directamente o de manera indirecta a las mismas, como sucede con las dos domus excavadas por P. París.

[13] O, grosso modo, al oeste de la habitación $\mathrm{n}^{\circ} 1$ según la propuesta de P. París. 
El límite septentrional de la factoría de salazones, que pensamos coincide con la trayectoria del Decumanus Maximus, debe ser planteado, por el momento, como una hipótesis de trabajo fundamentada en una serie de aspectos. Por un lado, el hecho ya comentado de la total inexistencia de restos arqueológicos al sur del citado eje viario no relacionados con actividades industriales vinculadas al mar, a excepción de los correspondientes tramos de muralla con sus respectivas torres. En segundo lugar deben ser tenidos en cuenta los restos arqueológicos de carácter industrial documentados más al norte, ejemplificados en el denominado Conjunto I, coincidente, en líneas generales, con la trayectoria de la última torre del tramo oriental de la muralla, así como las estructuras arqueológicas situadas al norte del Conjunto IV, poco perceptibles actualmente pero claramente visibles en la planimetría de G. Bonsor reproducida por P. París (1923, pl. I). Estos hallazgos, que definen una clara continuidad del trazado de la Calle de las Columnas hacia el norte, parecen evidenciar una funcionalidad similar para toda la zona meridional de la ciudad, o, al menos, no existe por el momento elemento alguno que permita contradecir esta propuesta. Adicionalmente, pensamos que las prescripciones legales vitrubianas o contenidas en la leges municipales del Alto Imperio (como puede ilustrar magistralmente la de Urso), así como los datos de la legislación tardía recopilados por R. Curtis ya citados encuentran su ejemplificación en Baelo Claudia en el aislamiento real que supone la localización del Barrio Industrial al sur de una vía que marcaba en el terreno el fin de una parte de la ciudad y el inicio de otro sector con una diferente funcionalidad. Confinamiento que, a pesar de acoger intra moenia las factorías de salazones, no facilitaba su fusión con las restantes zonas del urbanismo municipal.

El límite meridional del barrio industrial presenta una problemática específica. Ya hemos comentado anteriormente nuestra propuesta de considerar el limite perimetral sur de las domus y sus respectivas prolongaciones al este y al oeste como los restos de la cinta muraria baelonense, más de prestigio que propiamente defensiva, cuestión bien conocida en otros muchos casos hispanos. El aspecto que interesa poner de relieve a continuación es que las tres estructuras situadas en esta zona (las dos domvs y el Conjunto V) terminan exactamente coincidiendo con el percurso de esta unidad construida, y, al sur de ésta no se han localizado estructuras arquitectónicas de entidad, a excepción de algunos hallazgos puntuales que confirman la existencia de estructuras que debemos relacionar bien con restos industriales anteriores a la planificación urbana del "barrio industrial" o posteriores a su concepción urbana como espacio cívico bajo tutela del ordo decurionvm, bien con construcciones portuarias, en este último caso siguiendo la propuesta de las investigaciones más recientes (Alonso y Navarro 1997, 137-139). En cualquier caso, los restos arqueológicos aparecidos al sur de la citada unidad construida marcan un límite real que se corresponde con el final de las instalaciones industriales y el inicio de la ensenada de Bolonia.

El limite oriental es asimismo hipotético por el momento, ya que no se han podido realizar intervenciones arqueológicas bajo las construcciones situadas al este de la Casa del Cuadrante Solar, si bien la trayectoria de la muralla define con claridad una continuidad hacia el sur y suroeste que parece coincidir con la trayectoria de las estructuras de los conjuntos industriales que continúan en dicha dirección. Por tanto, la muralla debe coincidir con el límite de las estructuras industriales o las instalaciones anexas, tal y como sucede en el caso de la muralla meridional, a la cual se adosan las instalaciones industriales. Las 
citas de P. París relativas a hallazgos de posibles piletas junto a la necrópolis oriental de la ciudad no hacen sino confirmar esta propuesta, pues su interpretación debería ser análoga a la de los posibles restos portuarios aparecidos en la ensenada o, si queremos, como el caso de la lejana unidad de producción de Punta Camarinal.

Por último, el límite occidental del barrio industrial coincide, también en este caso, con la aparición de la muralla oeste de la ciudad, cuya trayectoria se desvía en dirección sureste a partir de la Puerta de Gades para adecuarse así a a la geomorfología del Arroyo de las Viñas. Los recientes sondeos realizados por el Conjunto Arqueológico en la zona meridional de la orilla izquierda del citado arroyo para confirmar la trayectoria de la muralla y su posible cierre meridional confirman la continuidad de la misma en coincidencia con las instalaciones industriales, como ya comentamos anteriormente, por lo que esta propuesta parece, por tanto, cobrar más énfasis. Pensamos que es pronto para decantarse por la posible funcionalidad de los restos arqueológicos existentes en la margen derecha del Arroyo de las Viñas, en la cual los hallazgos de piletas son evidentes, según se puede deducir con claridad de los resultados de los sondeos realizados en los años setenta por C. Domergue. Probablemente se trate de instalaciones portuarias o de uso mixto, si bien resulta necesario un estudio monográfico de la zona para extraer información contundente al respecto. Lo que sí queda claro es que todo ese sector quedaba claramente extramuros de la ciudad, y alejado por tanto de la dinámica urbana de la ciudad, por lo que consideramos prudente no incluir su problemática específica en estas páginas.

\subsubsection{La division interna del espacio industrial.}

Las factorías de salazones de Baelo quedan integradas en una gran superficie con tendencia a conformar un triángulo rectángulo, con su lado largo coincidente con la trayectoria del decumanvs maximvs de la ciudad. Es decir, unos $300 \mathrm{~m}$ de longitud máxima al norte y un centenar de metros de anchura, por lo que teniendo en cuenta la reducción de su perímetro al oeste por la trayectoria de la desembocadura del arroyo de las Viñas, la extensión total del Barrio Industrial debe comprender unos $20.000 \mathrm{~m}^{2}$ circa $^{[14]}$. En el estado actual de nuestros conocimientos son tres las partes que integran el urbanismo del Barrio Industrial, guiados por la trayectoria de los ejes viarios conservados, los cuales definen tres grandes espacios en dirección norte-sur que son los que detallamos a continuación.

\subsubsection{Zona oriental del Barrio Industrial (figura 6).}

Aparece delimitada al oeste por la trayectoria de la denominada "Calle de las Columnas" (París et alii 1923, 120-128), que constituye uno de los cuatro cardines conocidos arqueológicamente del trazado viario de Baelo, siendo su denominación actual la del

[14] Consideramos conveniente no precisar en este momento las dimensiones exactas de los respectivos elementos integrantes del barrio industrial al encontrarse el estudio definitivo sobre los mismos en fase de desarrollo. 


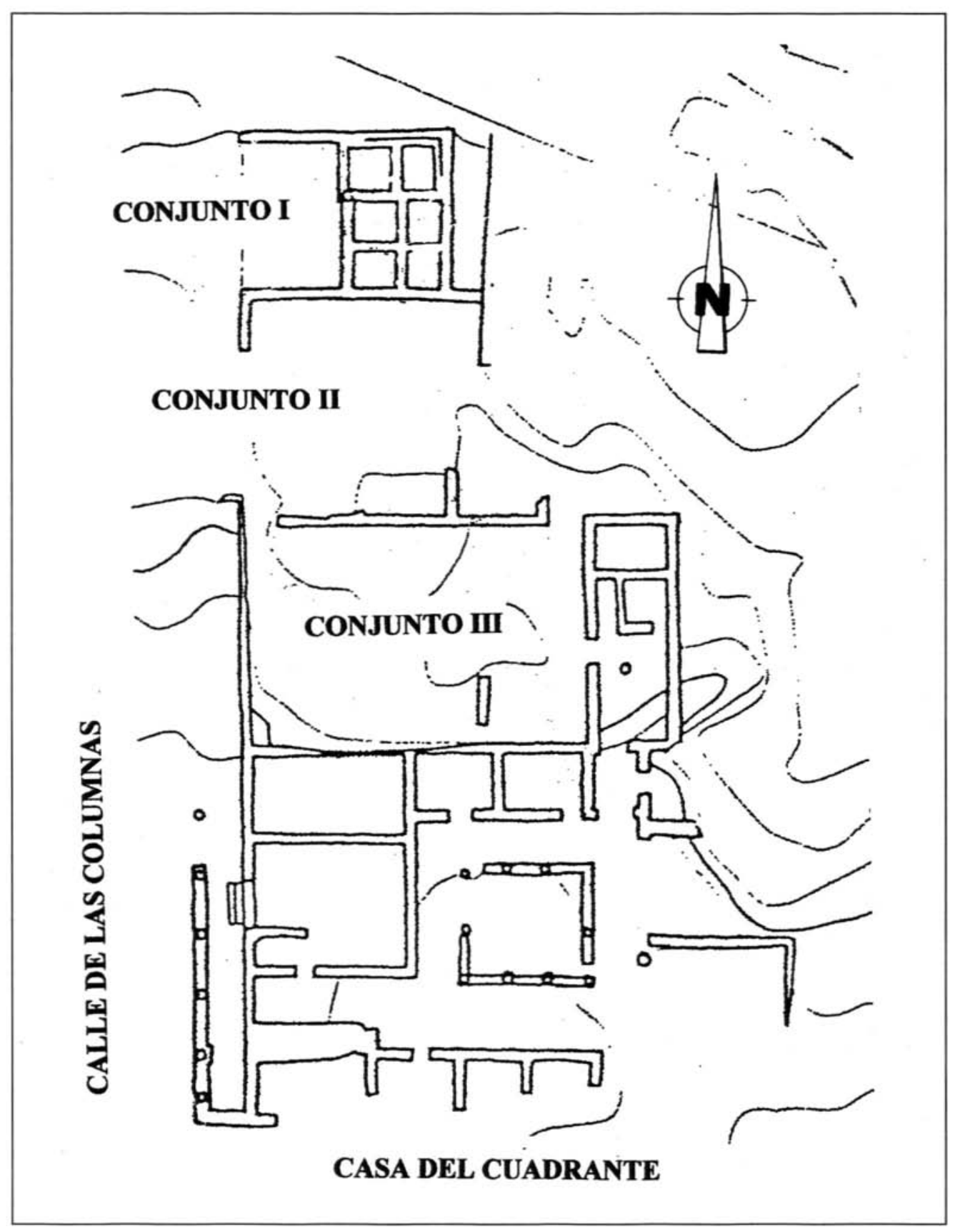

Figura 6. Zona oriental de la factoría con indicación de los Conjuntos Industriales I, II y III, así como la Casa del Cuadrante 
cardo 4 (Sillières 1995, 166, fig. 89). Éste se prolonga con claridad hacia el norte de la ciudad, una vez atravesado el decumanvs maximus, definiendo el límite oriental de la manzana del foro municipal. Se confirma, por tanto, que este eje viario de la factoría, porticado en su tramo meridional, constituye una de las vertebraciones internas del barrio coincidente con el momento de planificación urbana del asentamiento en el s. I d.C. Por ello, las estructuras documentadas al este de la Calle de las Columnas presentan una uniformidad estructural tal y como fueron planificadas en época romana, no habiendo sufrido grandes remodelaciones urbanas desde entonces, al menos aquellas que afectan a la fisonomía general de su planteamiento edilicio. Todas las estructuras situadas en la denominada Zona Oriental presentan fachada hacia la Calle de las Columnas, confirmando la propuesta planteada anteriormente. Componen esta parte de la factoría cuatro edificios netamente perceptibles, que son, de Norte a Sur los siguientes: Conjuntos Industriales I, II, III y Domus o Casa del Cuadrante. Todos ellos habían sido perfectamente identificados por P. París desde un punto de vista arquitectónico, a cuya propuesta únicamente queremos añadir una serie de valoraciones.

En primer lugar la evidente continuidad de los Conjuntos Industriales hacia el nòrte, en dirección al Decumanvs Maximvs, según se desprende de la planimetría general publicada por este investigador y que hemos podido comprobar durante el trabajo de campo. Por otra parte, de los tres Conjuntos Industriales definidos (I, II, y III) el I es claramente una Unidad de Producción, mientras que los C. II y III no presentan, por el momento, ningún elemento que permita confirmar dicha propuesta, que si bien esta la más probable no es posible confirmarla arqueológicamente por el momento. En tercer lugar, si bien hay detalles que confirman una planificación conjunta de la totalidad de las estructuras, básicamente los umbrales hacia la calle y la similar técnica constructiva en todos los casos, la morfología de los tres Conjuntos es diversa, y su módulo, variado. El C.I es el de menores dimensiones ( $5 \mathrm{mts}$. de anchura aprox.), siendo los C. II y III de similar anchura ( $7 \mathrm{mts}$. aprox.). En cuarto lugar, se advierte en los tres casos una proyección edilicia hacia el este, por lo que parecen integrar estructuras más complejas de las aparentemente representadas en el caso del C. I. Por último, se sitúa en la parte meridional de este sector la denominada Casa del Cuadrante, perfectamente integrada en el urbanismo de toda la zona y cuya relación con la factoría es evidente. Por un lado, esta construcción exponente del urbanismo privado de Baelo presenta en fachada al menos una habitación abierta hacia la Calle de la Columnas, la cual podría actuar a modo de taberna. Por otra parte, como ya puso en evidencia P. Sillières $(1995,167)$, la parte oriental de la casa está comunicada con las estancias traseras del C. III, por lo que la relación entre ambas dependencias es clara.

A nuestro entender, nos encontramos ante las viviendas de los probables dueños de parte de las industrias, los cuales habrían colocado su residencia en la zona meridional de la ciudad en íntima conexión con las factorías de salazones. En relación con las domvs, una cuestión que podemos avanzar es la perfecta integración urbanística entre las casas y los Conjuntos Industriales, por lo que dichos espacios, cuyo uso conjunto resulta poco canónico inicialmente, funcionaron de manera sincrónica. También queremos destacar el hecho de que ambas domus se edificaron en la parte baja del barrio industrial en la zona inmediata a la línea de playa, por lo que el contacto con las actividades industriales era necesario, pues el funcionamiento interno de la factoría obligaba al trasiego de pescado y mer- 
cancías hacia el puerto y viceversa y, por tanto, frente a las favces de la zona residencial. Pensamos que este factor es importante, pues si inicialmente las casas han sido evaluadas de manera autónoma y desvinculadas de las factorías de salazón, como se advierte de manera directa (París et alii 1923, 119-168; Silliéres 1991; 1995, 165-175) o indirecta -en este último caso obviando su presencia al evaluar la factoría- (Martín Bueno et alii 1984; Ponsich 1988), pensamos en nuestro caso que ambos tipos de estructuras arquitectónicas fueron preconcebidas en el mismo proyecto edilicio del barrio industrial y que funcionaron al mismo tiempo durante al menos parte de su existencia, sin que sea posible por el momento precisar más esta cuestión al tratarse de excavaciones antiguas sin referencias estratigráficas precisas.

\subsubsection{Zona central del Barrio Industrial (figura 7).}

Aparece delimitada esta zona con total nitidez al este por la Calle de las Columnas, pues las estructuras una vez más presentan fachada hacia el pórtico de la calle, y por el oeste por otro cardo de menor anchura (Sillières 1995, 166). Sí queremos aclarar que si bien la delimitación oriental es evidente que existía con similar disposición en época romana, el cardo que constituye el límite occidental de esta insula probablemente fosiliza un eje viario más antiguo (al coincidir su trayectoria con la parte central de la plataforma del foro), el cual se encuentra modificado por las factorías posteriores. Actualmente dicha vía urbana no comunica la ciudad con la línea de playa, encontrando el citado Conjunto V de Sillières a su paso. Es por ello que probablemente la disposición original de la planta del barrio industrial fuese diferente en esta zona, si bien el aspecto actual es el único que podemos interpretar actualmente, tal y como veremos a continuación.

Por un lado tenemos el denominado Conjunto IV, cuya estructura está bien definida, y que presenta el umbral de acceso a la Unidad de Producción orientado hacia el este, coincidiendo con la Calle de las Columnas. Al sur de esta zona central se sitúa la Casa del Oeste, con una disposición casi gemela a la de su vecina situada al otro lado de la calle. Remitimos a los estudios específicos de estas viviendas baelonenses para poder precisar sobre los detalles constructivos de las mismas (Silliéres 1991).

Junto a estos, han sido definidos dos Conjuntos Industriales más denominados V y VI respectivamente, definidos como ejemplos de las "grandes fábricas de conservas" (Sillières 1995, 182-185). Por el momento, y a esperas de ultimar un estudio integral del monumento, respetamos esta definición, teniendo en cuenta una serie de elementos que nos permiten en la actualidad considerar estas grandes fábricas como bastante tardías, probablemente del s. III d.C. en adelante, al menos tal y como se conservan en su apariencia externa actual. En relación con el C. VI, su construcción, al menos en la zona coincidente con las piletas circulares de sección troncocónica, provocó la parcial amortización de parte del peristilo y de la totalidad de las estancias situadas en el ángulo NO de la domus del oeste, tal y como se puede confirmar en las figuras 4 y 7 , por lo que su erección -como decimos en su estado urbanístico actual- es claramente posterior al momento de construcción de la casa. Por su parte, el C.V presenta un umbral septentrional con diversos niveles de amortización aún visibles en la actualidad, con el consecuente recrecimiento del nivel 


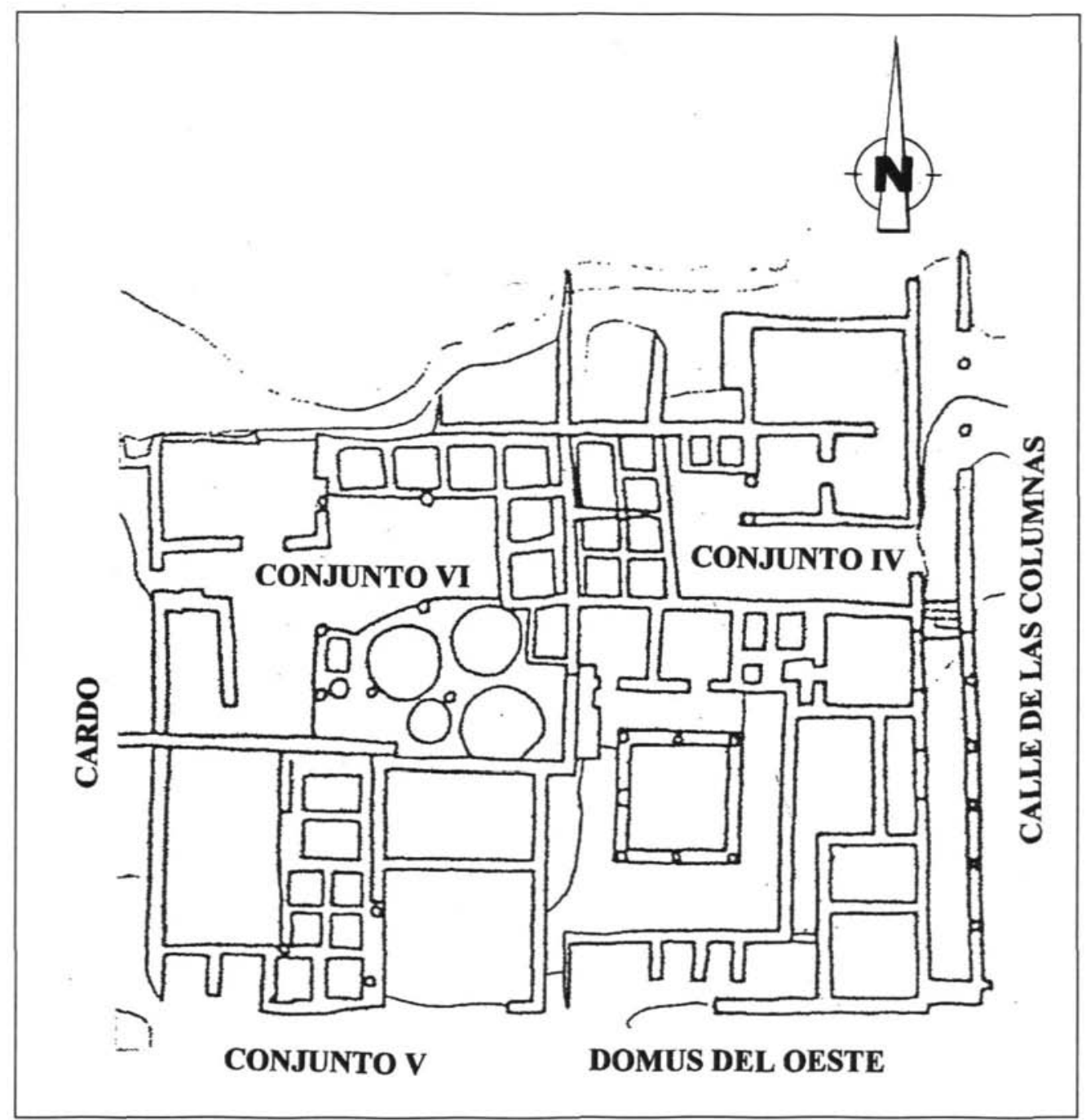

Figura 7. Zona central de la factoría con la indicación de los Conjuntos Industriales IV, V y VI, así como la Casa del Oeste

de pavimentación original del cardo. Pensamos además que inicialmente este cardo debía interconectar la zona alta de la ciudad con la zona de costa, por lo que el C. V se instaló encima de construcciones precedentes, amortizándolas ${ }^{[15]}$.

[15] Es posible confirmar arqueológicamente la existencia de unidades construidas más antiguas bajo la pavimentación de las estancias $\mathrm{n}^{\circ} 1$ y 2 del Conjunto $\mathrm{V}$, correspondientes con una fase anterior del establecimiento salsario. 
Respecto a la división interna de los dos Conjuntos citados, podemos decir lo siguiente por el momento. El C. VI presenta un único acceso desde el cardo situado al oeste, por lo que confirma que ésta era la zona de tránsito entre las factorías, al menos en la época de uso de los C. V y C. VI. Contamos con cuatro estancias que son las que fueron utilizadas como almacenes y como lugar para el desarrollo de las actividades industriales necesarias para la limpieza y preparación del pescado y los productos marinos, encontrándose los saladeros al final del conjunto, distribuidos en hilera en torno a las tres paredes. Resulta interesante destacar en este caso la alternancia entre piletas cuadrangulares y de planta circular, dando la impresión de que todas ellas se corresponden con la misma unidad de producción. Las dimensiones de este conjunto, de unos $270 \mathrm{~m}^{2}$ (18 x 15 mts.) son dobles respecto a otras factorías como sucede con el C. IV, cuestión que ha dado pie a que algunos investigadores hayan establecido la diferencia entre "grandes y pequeñas fábricas de conservas" (Sillières 1995, 179-185). Por su parte, el C. V es, por el momento, el más complejo desde un punto de vista de su concepción estructural. El principal problema que presenta es su articulación en torno al pequeño cardo del oeste. El final del tramo meridional de dicho eje viario aparece limitado por una puerta cuyo umbral da acceso a una zona mucho más alta respecto a la calle y completamente pavimentada con signinum (estancia $\mathrm{n}^{\circ} 10$ según P.París), siendo éste el elemento que permite interpretar los dos espacios a ambos lados de dicha estancia como pertenecientes a un único complejo industrial, ya que inicialmente da la impresión de que se corresponden con sendas zonas de trabajo independientes. Como se puede comprobar en la parte superior de la figura 4 , la gran habitación situada al este $\left(n^{\circ} 11\right)$ presenta a su vez un pequeño umbral al que se accede por una escalera con pocos peldaños, que da lugar a una zona de trabajo rectangular, encontrándose las diez piletas que conforman los saladeros dispuestos en torno a los muros perimetrales. Esta es la única zona del Barrio Industrial en la cual es posible reconstruir la totalidad de las partes aéreas del complejo, pues se encuentran las ventanas, que se corresponden con vanos de forma troncocónica con su zona de mayor anchura hacia el interior (fig, 2, supra), a modo de saeteras, al tiempo que se conserva el acceso adintelado al conjunto de una altura total de la estancia de $2,5 \mathrm{~m}$. Por último, la zona situada a la izquierda del conjunto ha sido excavada por debajo del nivel de pavimentación original, encontrándose ésta al mismo nivel que la parte derecha del conjunto, y en cuyo interior se advierten dos espacios cuadrangulares ( $\mathrm{n}^{\circ} 1$ y 2 en la planimetría de Sillières) con una serie de piletas al fondo, no siendo posible por el momento confirmar si estas últimas pertenecen al citado $\mathrm{C}$. V o constituyen la parte posterior de otra instalación industrial situada más al oeste.

\subsubsection{Zona occidental del Barrio Industrial (figura 8) y el macellum tardo- rromano.}

El espacio situado al oeste del cardo 4 y el límite propuesto para el cierre del barrio industrial, coincidente con la zona de muralla occidental de la ciudad, obliga a definir al menos una tercera zona, que probablemente tengamos que redistribuir en el futuro en más sectores debido a su notable extensión. Este es el sector en el cual se ha intervenido menos desde un punto de vista arqueológico, habiéndose exhumado las estructuras durante las 


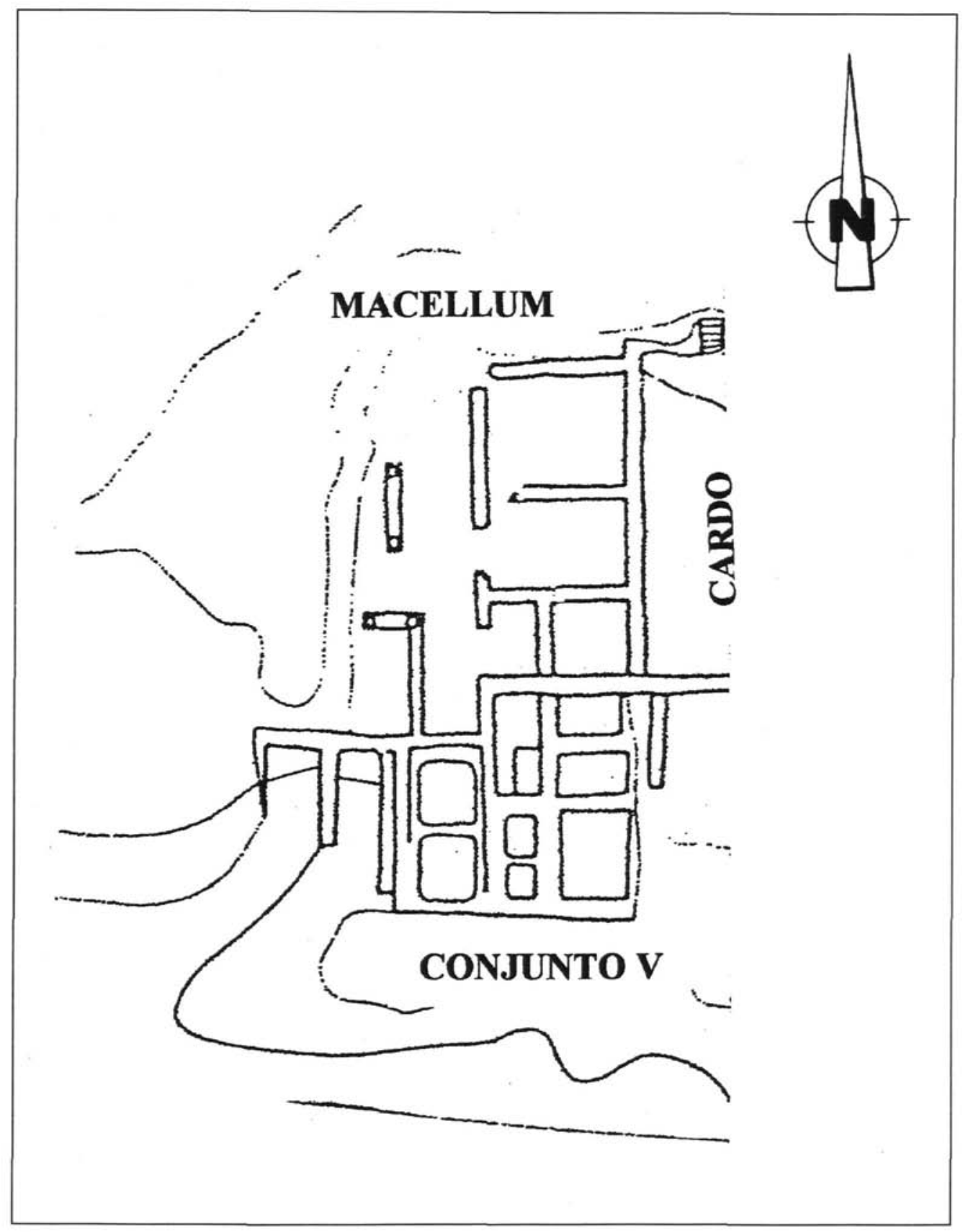

Figura 8. Zona occidental de la factoría con indicación del posible macellvm y de la zona parcial de otro conjunto industrial 
excavaciones de P. París únicamente hasta la parte alta de los muros, por lo que la estratigrafía se conserva intacta. En esta zona la continuidad de la factoría es evidente, si bien no se ha definido hasta la fecha ningún conjunto industrial específicamente, pues aparecen únicamente una serie de piletas en la parte más meridional del sector, si bien no es posible advertir las relaciones espaciales entre dichas estructuras ante la reducida extensión de la zona excavada. Por el momento podemos decir que existe al menos un Conjunto Industrial más al oeste del C. V y que se documentan los restos parciales de un pequeño edificio en la parte septentrional que había pasado desapercibido hasta la fecha en la investigación, por lo que nos detendremos a continuación en su descripción de manera más pormenorizada.

En la figura 8 se presentan los restos de edificaciones documentados en la zona occidental del barrio industrial, que deben ser divididos, como ya hemos comentado, en dos conjuntos netamente diferenciados. Por un lado, los situados al sur, continuando la trayectoria del muro perimetral norte del C. V, que remiten a los restos de otro conjunto industrial, según evidencian los restos de al menos seis piletas. Por otro lado, al norte del citado muro perimetral se advierte la existencia de una serie de estructuras que se caracterizan por los siguientes elementos. Por una parte, el citado muro perimetral septentrional del C. $\mathrm{V}$ permite intuir la existencia de un espacio claramente individualizado hacia el norte, ante la inexistencia de umbrales de comunicación entre ambas estructuras, aspecto que se confirma si tenemos en cuenta el completo aislamiento de estas edificaciones respecto al cardo adyacente. Efectivamente, las habitaciones documentadas presentan su parte trasera hacia el citado eje viario, adosándose a una unidad muraria perimetral bien conservada en altura que permite confirmar también en esta ocasión la completa inexistencia de comunicación alguna entre ellas y el cardo, aspecto confirmado adicionalmente por el acusado desnivel existente entre la pavimentación de esta vía y el suelo de las habitaciones que venimos mencionando, diferencia de cota superior a $1 \mathrm{~m}$ de altura total. Estos dos aspectos comentados confirman que nos encontramos ante la esquina conservada de un edificio con proyección estructural hacia el norte y el oeste, del cual únicamente se ha excavado -y conservado actualmente- su esquina suroriental. Estas estructuras no se advertían en la planimetría publicada por P. París, pues en la zona que nos ocupa únicamente se localizaban dos unidades murarias formando un ángulo recto, ni tampoco en la dada a conocer por $\mathrm{M}$. Martín Bueno. Ponsich reproduce exactamente las estructuras dadas a conocer por P. París, por lo que tampoco se documentan los restos objeto de atención en nuestras páginas. Únicamente encontramos en la planta de P. Sillières una serie de habitaciones situadas al norte del C. V, de las cuales no se detalla una explicación específica en el trabajo de síntesis, pero cuya interpretación planimétrica es clarividente (figura 9 A). Constituyen los restos de tres habitaciones, la más meridional de planta rectangular y las dos restantes prácticamente cuadradas con un módulo similar, todas ellas con umbral de acceso hacia el oeste, estando completamente aisladas del cardo que da acceso a los C. V y VI (Sillières 1995, 166, fig. 89).

Gracias al estudio detallado de la planimetría a escala del Conjunto Arqueológico, han podido ser advertidos otros detalles arquitectónicos (figura 9 B). Por una parte, junto a las tres habitaciones ya comentadas, cuyos umbrales están actualmente cegados como consecuencia de refacciones tardorromanas (tal y como se puede advertir en la habitación 


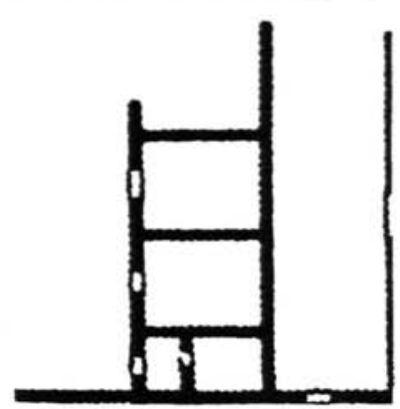

A

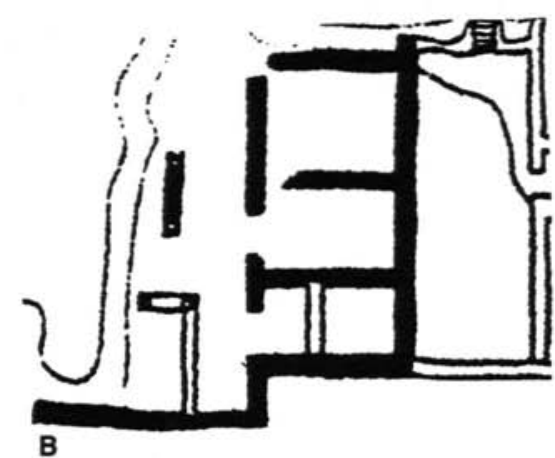

B

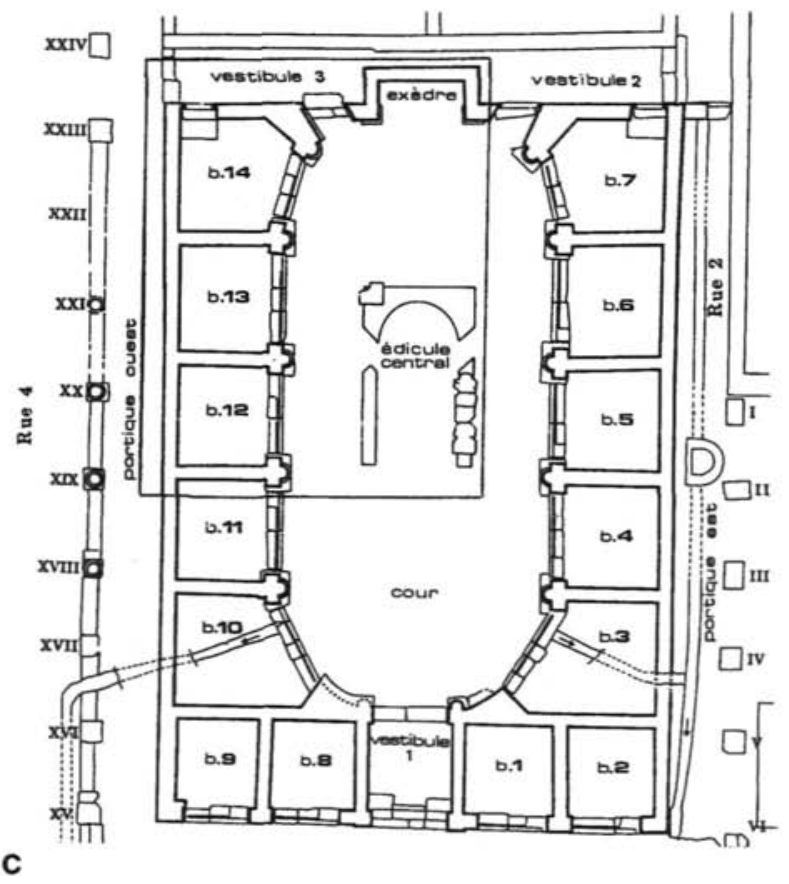

Figura 9. Estructuras relacionadas con el posible macellvm tardorrromano situado en el Barrio Industrial. A. Habitaciones situadas al norte de C.V. según Sillières $(1995,166)$. B. Detalle de las estructuras del macellvm según la planimetría del Conjunto Arqueológico. C. Zona detectada del macellvm en relación con la propuesta de reconstrucción de la planta del mercado altoimperial de Baelo. 
situada al norte y en la compartimentación interna de la situada al sur según la planimetría de la figura 9 B), se localiza una pequeña habitación cuadrangular al sur del conjunto, la cual está abierta e interconectada con la zona que da acceso a las otras tres estancias (fig. 9B, asterisco). Esta pequeña habitación se sitúa de manera perpendicular al eje de las estancias ya comentadas, y está abierta hacia el norte, apareciendo comunicada con un pasillo con las otras ${ }^{[16}$. El trabajo de campo ha permitido confirmar que delante de las tres habitaciones situadas en batería se localiza un pasillo rectangular completamente pavimentado con opus signinum, hormigón hidráulico que se conserva además en el interior de la pequeña estancia cuadrangular. Un tercer elemento arquitectónico ha contribuido sustancialmente a la interpretación funcional del edificio. Se trata de un conjunto formado por dos basas de columnas unidas entre sí por un fragmento de paramento realizado en incertum, con fragmentos de ostionera cuyo completo aislamiento de otras unidades construidas por el norte y el sur y, al mismo tiempo, la presencia en sus laterales de la citada pavimentación en signinum, permiten interpretar dichos restos como parte de una estructura de planta probablemente cuadrangular que delimita en torno a sus lados una zona de tránsito pavimentada con hormigón hidráulico. No es posible por el momento conocer más datos estructurales de este edificio ante la colmatación de toda la zona a partir de este punto hacia el oeste por sedimento, pues las excavaciones antiguas llegaron únicamente hasta este lugar de la factoría ${ }^{[17]}$.

A tenor de esta documentación un aspecto es evidente: estos elementos se corresponden con los restos de una edificación que no puede ser relacionada con una Unidad de Producción de la factoría de salazones. La completa inexistencia de piletas en toda la zona y al mismo tiempo la divergencia arquitectónica de la planta respecto a todas las factorías conocidas son dos argumentos de peso a dichos efectos. Con todo y con eso, de cara a la interpretación general del conjunto no hay que olvidar en ningún momento que este edificio está íntimamente relacionado con la factoría de salazones, al adaptarse su fisonomía a la disposición urbanística del Barrio Industrial, encontrándose relacionado con un Conjunto Industrial al Sur y con las factorías C. V y C. VI al sureste y al este respectivamente. Son dos las posibles interpretaciones que planteamos en un primer momento para esta edificación. Por un lado que se tratase de una vivienda, conscientes de la existencia de las dos domus ya citadas a ambos lados de la Calle de las Columnas, si bien dicha propuesta fue descartada inicialmente ante la escasa entidad de los elementos sustentantes centrales y, por tanto la imposibilidad de que se tratase de un "micro-peristilo". Al mismo tiempo, la interpretación de la pequeña habitación situada en el eje longitudinal de la construcción tampoco encontraba en esta línea una hermeneútica adecuada. Por el contrario,

[16] Por el contrario, en la única planimetría existente hasta la fecha en la cual se documenta esta habitación, la misma se presenta respecto a las tres habitaciones con umbral (Sillières 1995, 166, fig. 89), por lo que da la impresión que la misma pertenece estructuralmente al Conjunto Industrial infrayacente -situado al oeste del C. V- y no al edificio que estamos tratando como proponemos nosotros.

[17] La única zona que resta por interpretar es la situada al noroeste de la habitación cuadrangular, en la cual han sido repuestos los elementos arquitectónicos visibles actualmente, por lo que no resulta posible su correcta comprensión sin una intervención arqueológica exhaustiva en la zona. 
una serie de elementos permitieron definitivamente interpretar los restos aparecidos con la cuarta parte de un pequeño macellum.

Desde este punto de vista interpretativo y funcional cobran sentido las tres habitaciones de similar módulo con fachada hacia una zona pavimentada con signinum, las cuales actuarían a modo de tabernae. En segundo lugar, la pequeña habitación rectangular de reducidas dimensiones, y por tanto de un uso funcional poco viable, estaría remarcando el centro longitudinal del edificio, actuando a modo de exedra ${ }^{[18]}$. En tercer lugar, las dos basas con el elemento murario que las interconecta serían la parte inferior de los elementos sustentantes de una estructura que actuaría a modo de edículo central. Estos elementos cuadran perfectamente con los habituales en un macellum prototípico, siendo el propio ejemplo del mercado del foro de Baelo un paralelo arquitectónico clarividente en este caso (figura 9 C). La disposición del mercado en el Barrio Industrial, con la exedra hacia el sur, está delimitando indirectamente la existencia de un eje viario en dirección este -oeste al cual debía dar acceso este edificio, y que aún no ha sido localizado. Respecto a las dimensiones totales del mercado no debió ser mucho mayor en longitud del tramo conservado, al cual probablemente habría que adicionarle únicamente una habitación más al norte o directamente la línea frontal de tabernae orientadas hacia el eje viario, por lo que su longitud total sería de unos $15 \mathrm{~m}$ lineales aprox. en su eje mayor, detalle que permite plantear un modelo de mercado más pequeño que el macellum altoimperial del foro de la ciudad.

Respecto a la cronología del posible macellum contamos con pocos datos por el momento. La técnica constructiva utilizada para la construcción del muro perimetral oriental del mercado es un incertum que utiliza machones pétreos de gran tamaño de manera más o menos equidistantes, si bien no llega a tratarse de un verdadero paramento de opvs africanum, al menos en sentido estricto (figura 2, supra, izda.). En dicho paramento se ha podido localizar algún fragmento de TSG, probablemente de una copa de la forma Drag. 27, concretamente en la parte posterior de la habitación situada más al norte, el cual desgraciadamente da un terminus post quem de momentos muy avanzados del s. I d.C. o de inicios del s. II d.C. Otro detalle de interés lo constituyen los sistema de drenaje existentes en la parte inferior de la estancia más meridional del posible macellum y en el Conjunto Industrial V, los cuales estaban interrelacionados entre sí, detectándose una canalización conjunta que se sitúa bajo las estructuras aéreas de ambas edificaciones, como publicó en su momento M. Ponsich y ha sido posible confirmar durante el trabajo de campo. Por otro lado, las estructuras de la parte noroccidental del citado Conjunto Industrial V traban con las del edificio objeto de estudio, presentando una técnica edilicia similar y, aparentamente, una sincronía clara. El último detalle digno de mención es la amortización intencional de al menos dos umbrales de las habitaciones del mercado en época tardorromana, si tenemos en cuenta el tipo de materiales reutilizados -algunos sillares de ostionera y material constructivo fragmentario- y la disposición caótica de los mismos, cuyas analogías con las

[18] Únicamente resta por interpretar la parte occidental de la exedra que debería servir de elemento para la reconstrucción de la parte no excavada del edificio, por simetría especular. No obstante, las estructuras situadas junto a esta estancia así como la reposición de elementos arquitectónicos en las inmediaciones en fechas recientes no permiten, por el momento, una interpretación nítida. 
fases constructivas de reutilización de los edificios públicos y privados de la ciudad están bien fechados en los últimos siglos de la Antigüedad Tardía. Todos estos detalles nos inclinan a plantear una datación tardía para esta construcción, que probablemente debamos situar en momentos avanzados del s. II d.C. o incluso en época severiana. Sí parece claro que este edificio continúa en uso mientras lo están haciendo al menos las Grandes Fábricas de salazones de Baelo Claudia (C. V y C. VI), por tanto durante los ss. III, IV y V al menos. Las refacciones ya mencionadas en los umbrales de acceso a las estancias en momentos en los cuales este edificio ya probablemente no mantenía su actividad pública denotan su continuidad hasta finales de época tardoantigua, quizás el s. VI o incluso más tarde. Estas cuestiones deberán ser aclaradas con futuras intervenciones arqueológicas en la zona en los próximos años.

Desde un punto de vista funcional resulta muy acertada la presencia de un macellvm en una zona en la cual las industrias productivas constituían la clave del barrio industrial. Por tanto, su presencia en el Barrio Industrial de Baelo cobra, si cabe, aún más sentido atendiendo a esta óptica de interpretación. No es posible por el momento, si bien resulta tentador, considerar este edificio como el macellum de la ciudad a partir del s. III d.C. Tentador por lo que conocemos del macellum del foro, el cual es abandonado con fines comerciales desde finales del s. II d.C. hasta mediados del s. III d.C. (Didierjean et alii 1986, 78-103), por lo que este edificio del Barrio Industrial podría constituir el continuidor de una actividad comercial tan necesaria en esta ciudad hispanorromana del Conventus Gaditanvs. Por el momento no podemos confirmar si el macellvm del barrio portuario comenzó su actividad cuando aún el mercado del foro estaba en pleno funcionamiento, o bien si la erección del mismo fue una consecuencia del abandono del primero. Lo que sí podemos avanzar con cierta nitidez es el uso de este edificio durante el Bajo Imperio romano hasta momentos muy tardíos de la Antigüedad Clásica, posiblemente en coincidencia con el final de las actividades industriales en Bolonia.

Como habrá podido ser comprobado en este apartado, las dimensiones de las tres zonas del Barrio Industrial conocidas son discordantes, al tiempo que no resulta posible por el momento desglosar la articulación interna entre ellas, ante la ausencia de testimonios al respecto. Sí parece claro que las insulae conformadas por las instalaciones industriales parecen de mayor anchura que las habitualmente definidas entre los cardines de la parte central de la ciudad, si tomamos como modelo el único ejemplo completo existente, caso del módulo definido por la denominada Zona Central del Barrio. No obstante, las sucesivas remodelaciones internas de las unidades de producción durante el dilatado período de uso de la factoría no permiten por el momento un conocimiento detallado de la planificación urbana original de toda la zona meridional de la ciudad. Destaca la notable longitud de las insulae, como es posible ilustrar en el caso de la Zona Oriental de la factoría, al este de la Calle de las Columnas, cuya planificación incluye un frontal de al menos $50 \mathrm{~m}$ de longitud. Al mismo tiempo, resulta de interés documentar cómo las dimensiones en anchura de la Zona central del Barrio Industrial son ostensiblemente mayores que las de la Zona oriental, y es éste el único caso de la totalidad de la factoría en el cual se encuentran representadas las anchuras reales de la insula, si tenemos en cuenta las distancias intra cardines. Además, en este sector de la factoría se advierte la existencia de dos edificaciones enfrentadas, cada una de ellas con fachada a uno de los cardines que delimitan la insula, 
como ejemplifican magistralmente los Conjuntos IV y VI y, en menor medida, el caso pareado de la Casa del Oeste y el Conjunto V. De repetirse este esquema por todo el barrio industrial, aspecto que deberá ser confirmado en el futuro, tendríamos unas insulae de unos 120 pies de anchura ${ }^{[19]}$ ( $35 \mathrm{~m}$ de anchura aprox.) por una longitud superior a los 600 pies $^{[20]}$ (180 $\mathrm{m}$ aprox.). En ellas, se repetiría un esquema de edificaciones pareadas, con conjuntos industriales o instalaciones similares adosadas por su parte trasera y con ambas fachadas hacia los respectivos ejes viarios situados entre las insulae.

\subsection{Estudio e interpretación de las factorias: los Conjuntos Industriales I y IV}

El trabajo de campo realizado en el año 2000 en la factoría de salazones de Baelo Claudia ha permitido asimismo el estudio integral de la estructura arquitectónica de dos de las unidades de producción, que son los denominados Conjuntos Industriales I y IV (figuras 10 y 11). Vamos a presentar a continuación una serie de aspectos puntuales que nos permitirán de manera pormenorizada realizar una serie de valoraciones de carácter general sobre el barrio industrial de la ciudad ${ }^{[21]}$, teniendo en cuenta dos elementos básicamente: la. cronología de las factorías baelonenses y el modelo arquitectónico al cual se ajustan las mismas.

\subsubsection{La cronología de las factorias.}

Como ya hemos comentado de manera detallada en el apartado dedicado a la historiografía, los datos sobre la cronología de los Conjuntos Industriales baelonenses son escasos y notablemente contradictorios. Existe el consenso de que la actividad industrial comienza en época tardorepublicana (finales s. II o inicios del s. I a.C.), manteniéndose durante el Alto Imperio, llegando hasta momentos avanzados del s. IV o V para algunos autores (especialmente M. Ponsich y en menor medida M. Martín Bueno) o cesando su producción en momentos centrados en el s. III d.C., no encontrándose la vitalidad bajoimperial de la ciudad centrada en esta actividad (Sillières 1995, 188).

Una primera cuestión digna de mención es la notable dificultad que encontramos a la hora de extraer datos relacionados con la cronología de los establecimientos salsarios, pues a pesar de la minuciosidad de las intervenciones de P. París, las informaciones existentes son contradictorias. Baste consultar las recientes disquisiciones planteadas al hilo de la cronología de las domus baelonenses (Sillières 1995, 172-175) para contrastar cómo en

[19] Medida derivada de la distancia entre los respectivos umbrales de acceso entre el C. IV y el C. VI.

[20] Distancia existente entre la parte septentrional del C. I y el muro perimetral sur de la Domus del Cuadrante.

[21] Esperamos en el futuro poder presentar de manera analítica el estudio de los Conjuntos Industriales, aspecto que no puede ser tratado en estas páginas ante el ingente volumen de información disponible. 


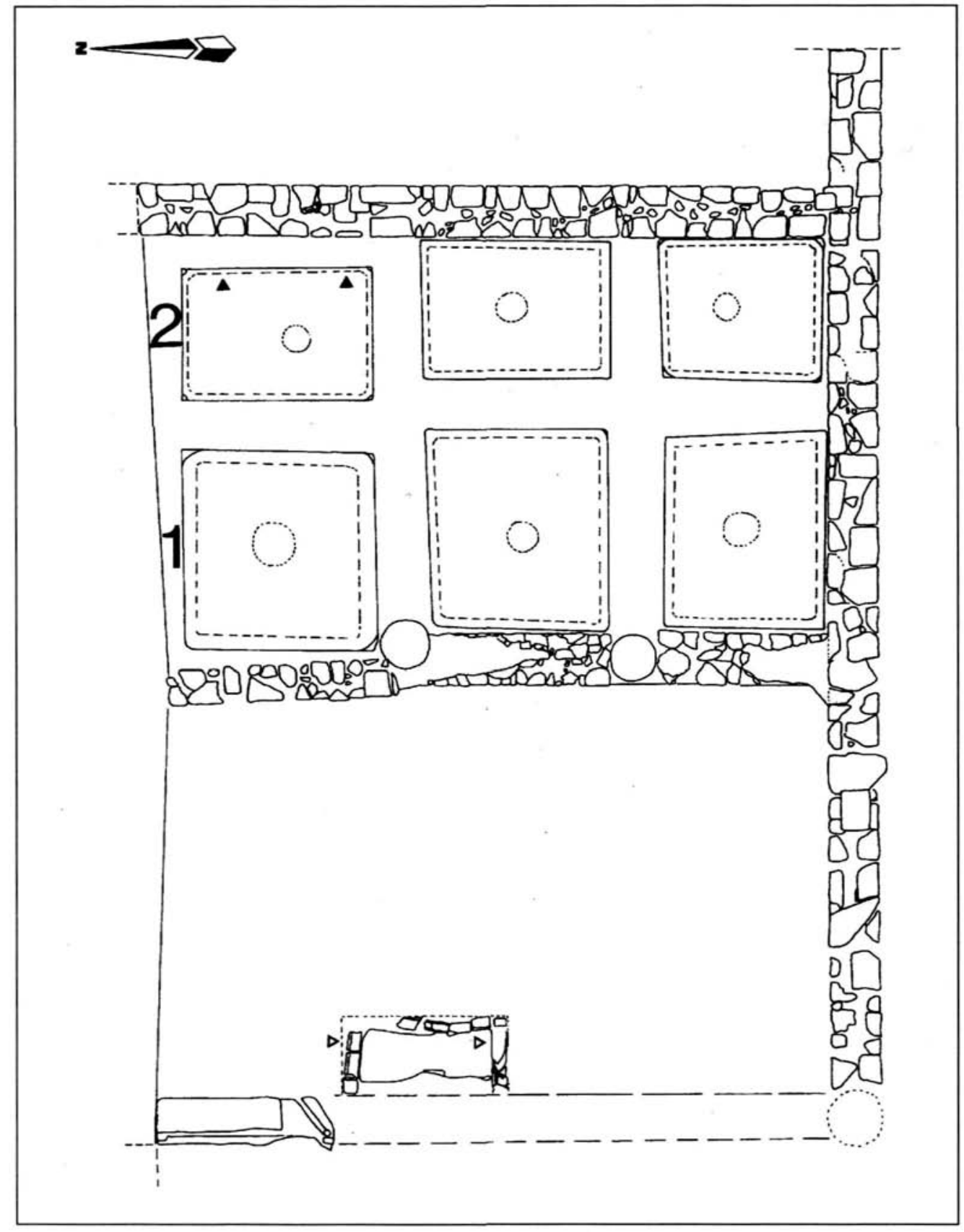

Figura 10. Planta general del Conjunto Industrial $I$, en la Zona Oriental del Barrio Industrial (Dibujo L. Aguilera) 


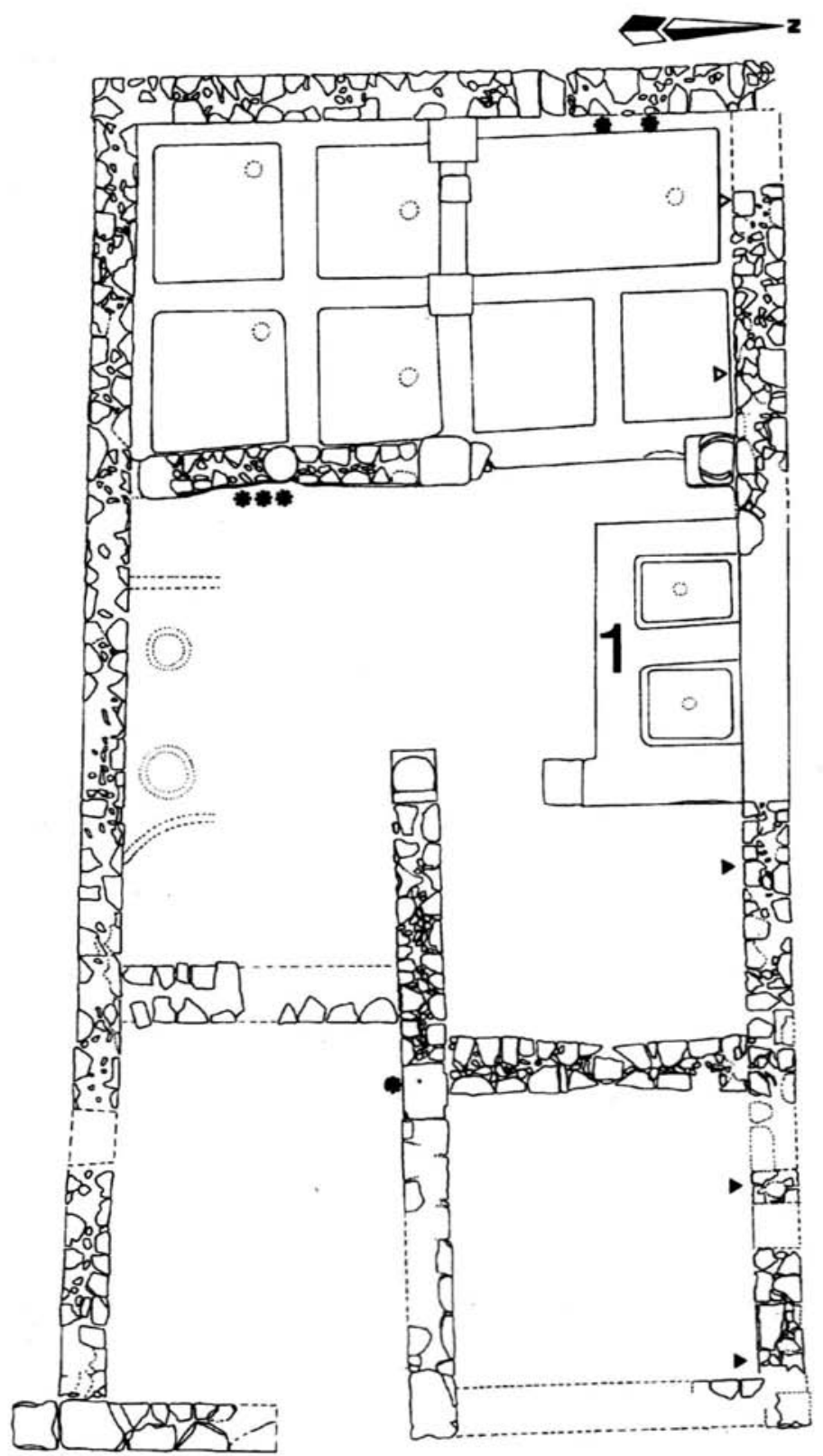

Figura 10. 1. Planta general del Conjunto Industrial IV, en la Zona Central del Barrio Industrial (Dibujo L. Aguilera) 
el caso de los conjuntos industriales los datos son tan contradictorios como aquellos, e incluso menos explícitos aún.

La información disponible en la actualidad se limita a una serie de testimonios directos o indirectos que permiten plantear, al menos en el caso de los C. I y C. IV, una serie de detalles puntuales que permiten extraer datos cronológicos concretos sobre los citados conjuntos industriales, si bien resultaría utópico tratar de plantear en la actualidad un conocimiento cronológico exhaustivo de las diversas fases de la factoría sin recurrir a intervenciones arqueológicas que permitiesen avanzar en dicha propuesta ${ }^{[22]}$. Es por ello que nuestro estudio ha tratado de aunar aquellos datos útiles a efectos cronológicos, siendo nuestra única intención por el momento sentar las bases que trabajos posteriores deberán matizar.

Hemos recurrido a dos tipos de elementos para avanzar en esta cuestión: los elementos datantes directos y el estudio comparado de la técnica edilicia. Vamos a presentar a continuación de manera sintética los resultados obtenidos y el estado actual de nuestros conocimientos sobre estas unidades de producción de la factoría de Baelo Claudia.

En relación con el origen de las industrias conserveras en la ciudad, la información disponible en la actualidad se sigue limitando a los contextos estratigráficos obtenidos en los sondeos realizados por $\mathrm{C}$. Domergue, por lo que unos inicios en momentos muy avanzados del s. II a. C. o a principios del s. I a.C. es la fecha más probable. Por lo que sabemos, en dichas fechas las actividades industriales se concentran en el entorno de la Puerta de Gades y en la margen derecha de la desembocadura del Arroyo de las Viñas, a tenor de los sondeos estratigráficos mencionados anteriormente. No existen testimonios directos sobre la cronología de instalación de las primeras fábricas salazoneras en el barrio meridional. Básicamente por dos motivos. Las intervenciones arqueológicas realizadas a todo lo largo de la extensión de la ciudad baja se han limitado a la excavación de los niveles de amortización de las piletas o en general de las habitaciones de las unidades de producción, por lo que han permitido exhumar las estructuras de las factorías una vez planificado urbanísticamente el Barrio Industrial, y no las más antiguas. Únicamente contamos con los dos sondeos estratigráficos ya citados de M. Martín Bueno en la Calle de las Columnas y en la parte meridional de la Casa del Oeste, habiendo aportado el primero de ellos una secuencia estratigráfica que comienza en torno al Cambio de Era (Martín Bueno et alii 1984, 489496). Otro aspecto importante es que tras un estudio integral y detallado de la factoría de Bolonia se advierte la existencia de estructuras arqueológicas de entidad bajo las construcciones actuales. Este aspecto se puede comprobar especialmente en la zona occidental del C. V (Sillières 1995,166 , fig. 89, C. V, $\mathrm{n}^{\circ} 1$ y 2 ) pues las excavaciones de P. París llegaron por debajo del nivel de pavimentación de la factoría citada, apareciendo en un nivel inferior restos de unidades murarias que evidencian construcciones de entidad previas a la construcción de la factoría citada. Sí resulta significativa la total ausencia de materiales de época republicana en los sondeos realizados por M. Martín Bueno, por lo que tendemos a

[22] Con motivo de la realización del II Curso Internacional de Arqueología Clásica en Baelo Claudia ha sido solicitada la realización de una Actuación Arqueológica Puntual en el Conjunto III y en el VI para tratar de solventar la problemática de la génesis y la amortización de estas instalaciones. 
pensar que la plataforma ocupada actualmente por el Barrio Industrial no debió tener una ocupación intensiva en época romano-republicana. Con la prudencia derivada del tipo de información existente, pensamos que en época preaugustea las factorías debieron estar diseminadas en torno a la línea de playa, sin que se procediera a una articulación del espacio bien definida hasta momentos posteriores.

La siguiente cuestión importante radica en plantear el momento de construcción del barrio industrial, que consideramos una empresa edilicia amparada por las autoridades municipales y directamente relacionada con el urbanismo de la ciudad. Así entendida la erección de un auténtico barrio industrial en la zona baja de la ciudad, cobra sentido su localización intra moenia y la existencia de arterias viarias que comunican las diversas partes de la ciudad con el barrio portuario. La pregunta que inmediatamente surge es si esta propuesta que planteamos deriva únicamente de la lógica o encontramos testimonios arqueológicos claros que permitan apuntalarla. Para responder a ello, tenemos que acudir al urbanismo existente en la totalidad de unidades funcionales definidas en el Barrio Industrial. Ha podido ser detectada una dinámica constructiva según la cual los ejes planteados en la articulación interna del espacio del barrio industrial se mantuvieron prácticamente inalterados desde su origen hasta el abandono de los complejos salsarios, salvo excepciones muy concretas. Es por ello que en la totalidad de Unidades de Producción estudiadas se han detectado REFORMAS EDILICIAS de notable entidad, las cuales respetan los espacios y la orientación de los muros perimetrales de los conjuntos anteriores. Veamos algunos ejemplos al respecto.

En el Conjunto I se ha detectado la sistemática reutilización de las unidades perimetrales que lo conformaban, como consecuencia del dilatado uso de estas instalaciones a lo largo del tiempo. Es por ello que se advierten una serie de recrecimientos de los citados muros perimetrales, que denotan procesos de reforma del conjunto industrial que han respetado en la totalidad de los casos la ortogonalidad de la trama constructiva primigenia. Así se puede contrastar en el caso del paramento externo del muro perimetral sur del C. I (o límite entre el C. I y el C.II), cuya parte inferior visible se construyó en vittatum de caliza gris y areniscas diversas y cuya parte superior es un recrecimiento de caliza fosilífera propio de época tardía (figura $12 \mathrm{~A}$ ). Incluso las actividades edilicias necesarias como consecuencia del deterioro de las industrias han respetado milimétricamente la articulación primigenia del espacio. A través del estudio de detalle de la técnica constructiva de las piletas del C. I se ha podido documentar una reforma acontecida en las dos piletas situadas en la parte septentrional del conjunto, frente a la zona de acceso a la factoría (figura 10, 1 y 2). Inicialmente la planta publicada de la factoría presentaba 6 piletas cuadradas casi gemelas, con módulo prácticamente idéntico. Un estudio detallado de la planimetría ha permitido detectar la existencia de una perfecta homogeneidad de las cuatro piletas situadas al sur, habiéndose procedido en un momento posterior al vaciado del tercio norte de la zona del saladero, eliminando las dos piletas septentrionales, construyendo un murete de refuerzo de la pared perimetral oriental del C.I (figura 10, flechas negras; fig. 12 B), hecho que provocó una disimetría estructural de las piletas 1 y 2 respecto a las demás, detalles perceptibles en el descuadre existente en los muros medianeros entre todas las piletas del conjunto $\mathrm{y}$, asimismo, en la pared occidental de la pileta 1 , que se adelanta hacia la zona pavimentada con signinum, en dirección al umbral del complejo. Adicionalmente, se advierte 


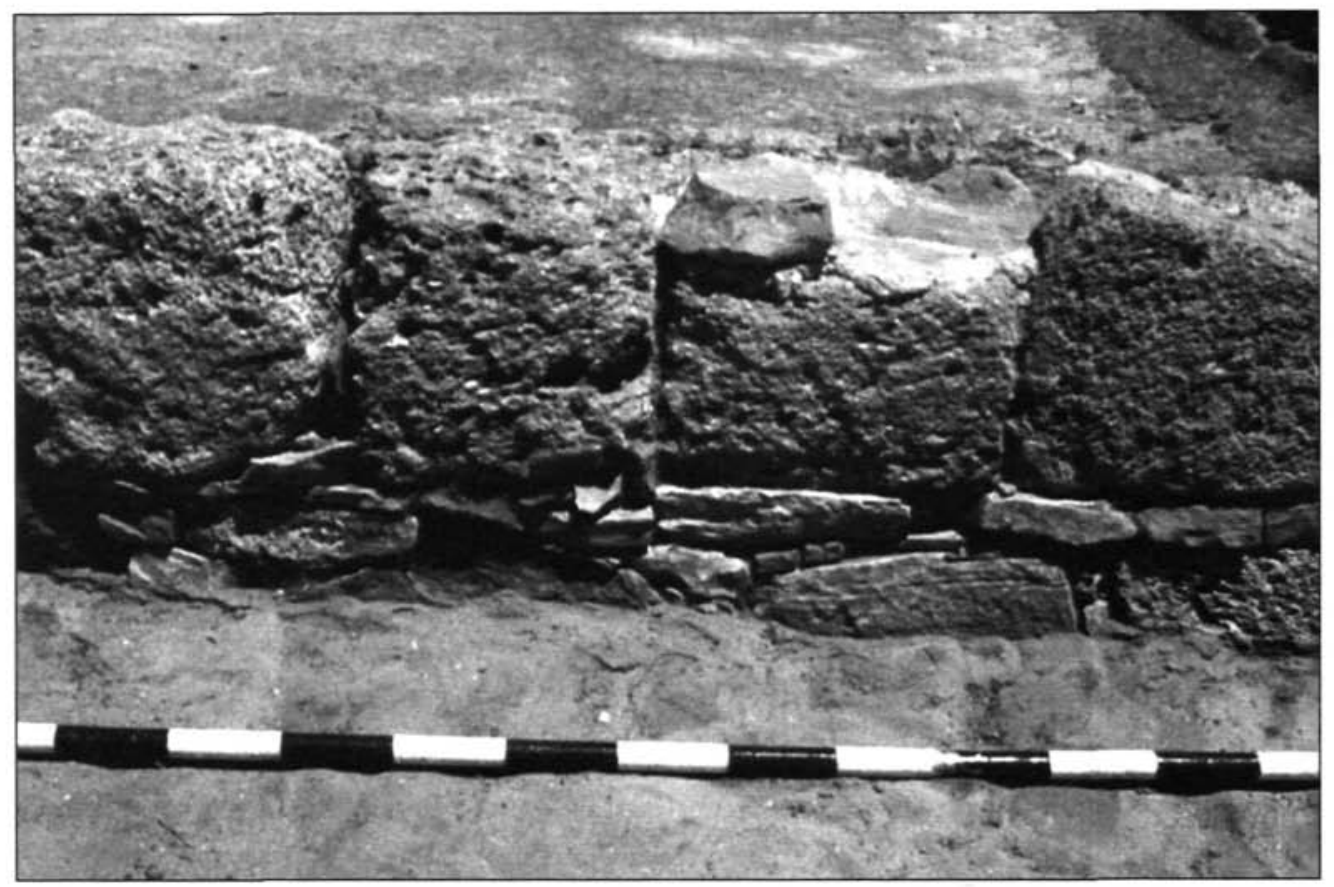

Figura $12 \mathrm{~A}$. Detalles constructivos del Conjunto Industrial I. Parámetro frontal meridional del muro perimetral sur, con opes vittatum en la parte inferior y un recrecimiento de ostionera en la parte superior.

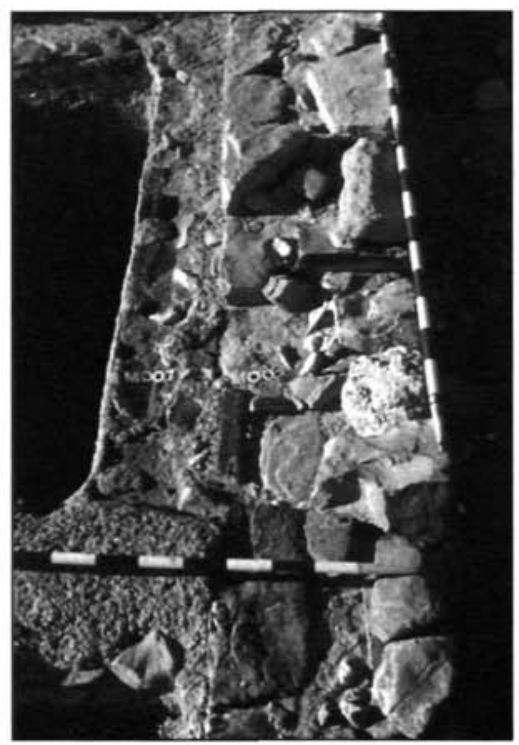

Figura $12 \boldsymbol{B}$. Detalles constructivos del Conjunto Industrial I. Detalle de la zona de unión de la pilera nororiental del C.I. con el muro perimetral este del citado conjunto, con la indicación del recrecimiento murario hacia el interior de la cubeta tras la reforma. 
en estas dos piletas más tardías ( $n^{\circ} 1$ y 2 ) la existencia de modillones verticales de cuarto de bocel en signinum, elemento claramente de modernidad en la edilicia industrial baelonense, aspecto que confirma la tendencia constructiva advertida. Otro detalle que ratifica la dilatada vida de estos saladeros de pescado son las sucesivas capas de signinum que pueden documentarse en estas cubetas, resultados de las diversas refacciones como consecuencia de un deterioro asociado a un prolongado e intenso proceso de trabajo, siendo estos detalles especialmente perceptibles en la zona baja de las paredes, previamente al inicio del modillón de cuarto de círculo, o en las roturas recientes del enfoscado de la pared. Un elemento datante de interés ha sido la localización en algunos puntos del signinum de las paredes de algunas de las piletas del C. I de fragmentos de cerámica africana de cocina reutilizados en la ejecución de esta capa de mortero, por lo que una datación post quem a época flavia puede ser planteada para la realización de dichos revocos, momento a partir del cual parecen comercializarse estos productos a Hispania desde el norte de África Proconsular (Aguarod 1991; Aquilué 1998).

Otro aspecto detectado durante el estudio de la factoría I ha sido la localización una serie de materiales constructivos latericios en una pequeña cubeta situada a la entrada de la Unidad de Producción (figura 10 A). Esta pileta había sido relacionada por sus dimensiones con un pequeño depósito para la elaboración de garvm u otras salsas de pescado y mariscos. Independientemente de su funcionalidad, que probablemente debamos relacionar más bien con la contención de agua al no existir depósitos hídricos subterráneos en esta factoría, su estudio detallado ha permitido comprobar que bajo la capa de signinum impermeabilizante que recubre las paredes de esta instalación, se utilizaron materiales constructivos de diversa naturaleza entre los cuales se reutilizaron ladrillos fragmentados para su erección. Concretamente, ha sido posible documentar restos de más de una veintena de testae, normalmente en estado fragmentario, algunos de los cuales se ajustan a un prototipo característico de ladrillo propio de las concamerationes de los edificios termales (figura 13 B). Se trata de ladrillos de módulo rectangular con doble rebaje longitudinal utilizados para crear dobles paredes en las estancias calefactadas de los complejos termales para permitir la subida del aire por las mismas y mantener una temperatura más elevada en los caldaria balnearios (Brodribb 1991), contando con ejemplos cercanos de este tipo de testae en casos como las termas de Gandori en la orilla tingitana (Ponsich 1970, 380-386). La cuestión que nos interesa a continuación es únicamente aquella de la cual se derivan inferencias cronológicas: al menos dos de los ladrillos reutilizados en la construcción de esta pileta del C. I llevaban marcas, concretamente IMP.ACR en un caso e IVL AVG en otro (figura 13 B y C). Huelga incidir sobre una de las cuestiones más conocidas de la arqueología baelonense, cual es la importancia de los elementos latericios aparecidos en las pilae de la bipocausis de sus termas públicas, cuyas marcas llevaron a los investigadores a plantear una zona de origen tingitana para los mismos, permitiendo consolidar en su momento la existencia de unas activas relaciones comerciales entre la Baetica y la Mauretania Tingitana (Etienne y Mayet 1970; Ponsich 1970, 264-272). Aparte de las implicaciones de estos hallazgos, que plantearemos más adelante en otros trabajos monográficos, la inferencia cronológica más clara es que el uso de ladrillos de morfología termal con sellos análogos a los del establecimiento balneario del decumanus en Baelo Claudia reutilizados en la construcción de la pileta del C.I permiten aportar un terminvs post quem evidente para la construcción 


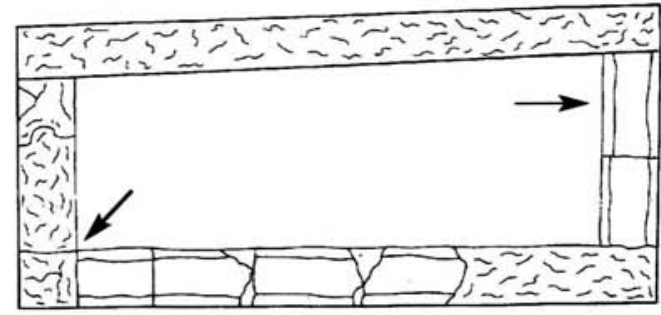

A

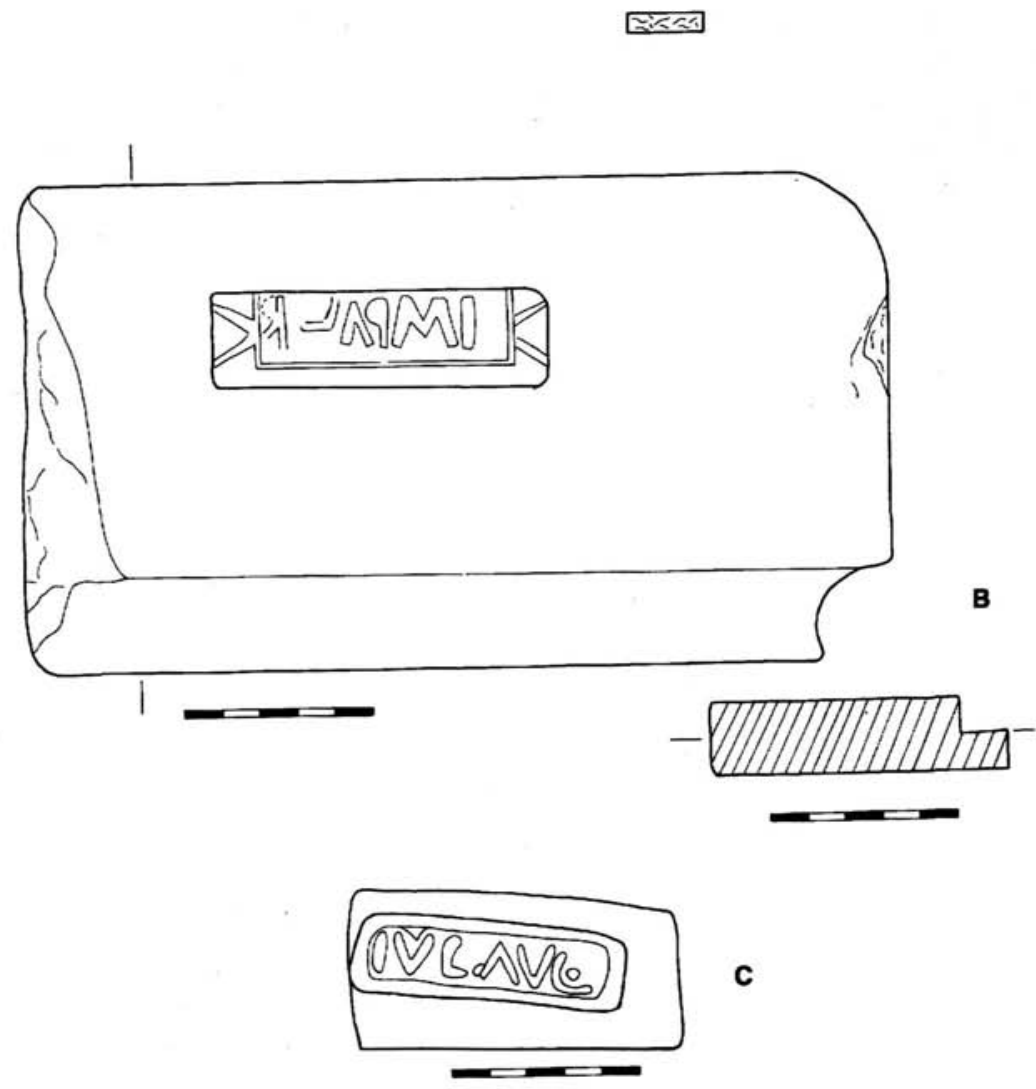

Figura 13. Detalle de los materiales constructivos de la pilera cuadrangular del C.I. con los sellos latericios (dibujo de L. Lorenzo). A. Planta de la pileta rectangular, con indicación de los ladrillos reutilizados. B. Ladrillo de termas con la marca IMP ACR (retro) in tabula ansata. C. Detalle del ladrillo con la marca IVL.AVG en cartela rectangular. 
de dicha instalación auxiliar en la factoría. Conociendo que la cronología de las termas se sitúa actualmente en la primera mitad del s. II d.C. (Sillières 1995, 161-162), o en cualquier caso en torno a finales del s. I o inicios del s. II d.C. ${ }^{[23]}$, frente a la tradicional datación bajoimperial para las mismas, la reutilización de materiales constructivos de dicha época en el C. I es claramente inmediato o posterior a dicho momento.

Por su parte, en el C. IV han sido detectadas una serie de actividades constructivas que denotan una tendencia similar. Probablemente la más significativa es la que afecta al muro perimetral norte del complejo. Esta unidad muraria (figura 11, flechas) marca uno de los ejes ortogonales más claros de todo el barrio industrial, pues conforma el límite superior de los C. IV y del C. VI al mismo tiempo. El estudio de la técnica constructiva del mismo ha permitido detectar una primera fase realizada a base de pequeños bloques de caliza gris bien escuadrados, de forma normalmente rectangular y puntualmente cuadrangular, siendo estos especialmente visibles en el tramo más oriental del mismo (fig. $14 \mathrm{~A}$ ). Esta misma unidad muraria presenta a todo lo largo de su recorrido dos técnicas constructivas más, siendo perceptible el incertum en calizas y areniscas de diversa colorimetría, e incluso una refacción tardía realizada con ostionera en su parte más occidental, concretamente en el tramo de las piletas (fig. 11, flechas blancas). Esta U.E. constructiva ha mantenido su misma trayectoria durante la totalidad del período de uso de las instalaciones industriales, como permiten confirmar las sucesivas reformas de este muro perimetral respetando milimétricamente la dirección de las estructuras primigenias y, por tanto, la urbanística de la insula en la cual se integra. No hace falta recordar que el vittatum de caliza gris en Baelo se relaciona con estructuras propias de época augustea o julio-claudia, encontrando en la Basilica del foro el ejemplo más clarividente (Sillières 1995, 84 y 106-119). Asimismo, el incertum o pseudo-vittatum de caliza y arenisca de diversa colorimetría, que constituye el tipo de aparejo más frecuente en la factoría, se relaciona con construcciones de momentos muy avanzados del s. I o de principios del s. II d.C., siendo el macellvm el prototipo arquitectónico que ha permitido marcar esta tendencia (Didierjean et alii 1986). Por último, las refacciones murarias utilizando material constructivo reutilizado y fragmentos de roca ostionera son propias de las actividades edilicas del Bajo Imperio, ejemplo clarísimamente ilustrado en multitud de edificaciones baelonenses, siendo magistral el caso de las casas situadas sobre el Isevm y el Macellvm en pleno s. IV d.C. (Sillières 1995, 178, fig. 99 y 100). La integración de estas tres técnicas edilicias en la misma unidad construida en el C. IV es un testimonio clarividente de dos cuestiones: la dilatada vida del conjunto industrial -época julio-claudia hasta bien entrado el Bajo Imperio- y el mantenimiento de los mismos ejes urbanísticos en la factoría -y por extensión en la insula y por tanto en todo el Barrio Industrial- a lo largo de la totalidad del periodo productivo.

Junto a estas cuestiones estrictamente relacionadas con la técnica constructiva del edificio, hay otros elementos que confirman las remodelaciones de la factoría en época tardoantigua. Por un lado contamos con el adosamiento al muro perimetral norte de dos pile-

[23] Agradecemos profundamente a D. F. Alarcón habernos proporcionado este dato inédito procedente de las reciente intervenciones en estructuras situadas en la misma insula que las termas, cuya datación parece situarse en estos momentos. 
tas cuadrangulares de reducidas dimensiones (figura 11 A), cuyos muretes están realizados con ostionera mezclada con mampuestos de diversa naturaleza, técnica constructiva propia de época bajoimperial o posterior en esta ciudad ribereña del Estrecho. Además, el reducido tamaño de estas piletas (cercano al metro cúbico de capacidad), su escaso número (2 ejemplares únicamente), la presencia de modillones verticales de signinum en los cuatro ángulos de sus paredes y el paralelismo tipológico con otros conjuntos bien fechados como sucede con la facies bajoimperial de la factoría tingitana de Septem Fratres (Bernal y Pérez 1999, 46-48, fig. 20, lám. XIII), permiten considerar esta reforma como tardorromana, pudiendo datarla probablemente a partir del s. IV d.C., con las reservas oportunas. La invasión de la parte noreste de la Casa del Oeste con otro conjunto de dos piletas análogas (fig. 4 infra, entre $n^{\circ} 23$ y 27) parece responder también a la ampliación del C. IV hacia el sur en estos mismos momentos, si tenemos en cuenta el nivel de utilización de las mismas, que coincide exactamente con el de las cubetas pareadas que hemos visto antes, así como la facilidad de acceso y relación funcional de las mismas con la sala de trabajo del C. IV.

Si bien insistimos en el hecho de que la evolución interna de la factoría respeta los ejes ortogonales de las insulae en las cuales se encuentran instaladas, no documentándose en ningún caso de los conservados alteraciones de la dirección de las unidades murarias posteriores respecto a las primigenias, salvo casos muy puntuales bien localizados, el dinamismo interno de las factorías sí provoca remodelaciones internas que en ocasiones afectan a la totalidad de la planta del complejo y, más frecuentemente, se traducen en reformas puntuales del proceso de compartimentación interna de las habitaciones. Por poner un ejemplo de cada caso, la fisonomía actual del C.IV no debió ser la misma en todas las fases de vida de esta unidad de producción, pues la disposición del muro perimetral oeste está amortizando parte de un antiguo pavimento de signinum que confirma una continuidad inicial de la factoría hacia Poniente (fig. 11, 2 asteriscos; fig. 14 B). Asimismo, si da la impresión inicial que la planta del C. IV siempre tuvo cuatro pequeñas estancias delante de la zona de piletas destinadas a la limpieza y despiece del pescado, esta propuesta no puede ser mantenida a la luz del estudio arqueológico de las estructuras, pues hay habitaciones que inicialmente no existían y que se corresponden con compartimentaciones posteriores. Un ejemplo nítido de este proceso está ejemplificado por la pequeña estancia situada en el lateral norte de la factoría con fachada hacia la Calle de las Columnas, cuya tabicación interna actual es de época tardorromana, pues ésta se encuentra amortizando una base con pilastra (fig. 11, 1 asterisco) que probablemente en origen daba acceso a un espacio abierto, reforzando la estructura de las paredes y ornamentándolas. Un último aspecto que sí queremos poner de manifiesto de cara a valorar el dinamismo constructivo de las factorías baelonenses es la frecuente reutilización de material constructivo en las edificaciones posteriores: de esta manera, han aparecido restos de elementos arquitectónicos realizados en caliza fosilífera embutidos en los paramentos de varios muros: una basa con doble moldura en el muro divisorio de las piletas (fig. 11, 3 asteriscos) y un capitel en la parte posterior del muro trasero del C.IV, o una cornisa en el paramento que delimita el C. II del C.III.

Con estos datos planteados de manera concisa, es el momento ahora de hacerse la siguiente pregunta ¿cuándo se procede a la planificación urbana del Barrio Industrial? Nuestra impresión actual permite plantear que la mayor parte -si no todo- el barrio industrial se planifica y construye en época augustea o, a más tardar en momentos julio-claudios 

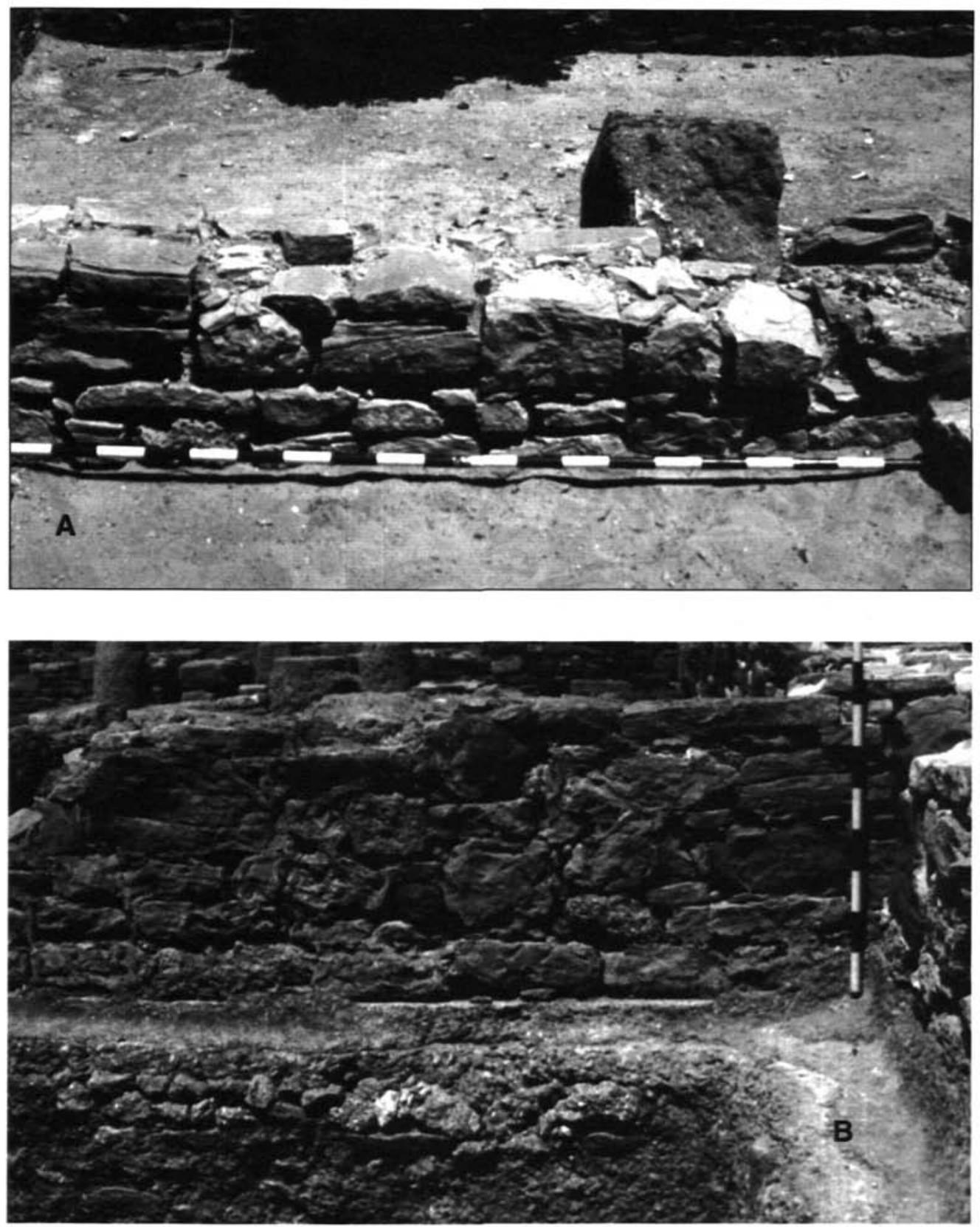

Figura 14. Detalles constructivos del Conjunto Industrial IV. A. Paramento frontal del muro perimetral norte realizado en vittatum de caliza gris. B. Parámetros de incertum de caliza y arenisca en el ángulo noroccidental del C.IV, con un detalle de la amortización de un suelo de signinum anterior a la construcción general del espacio. 
iniciales. Así permiten plantearlo tanto el inicio de la estratigrafía obtenida frente al Conjunto Industrial III en torno al cambio de Era por el equipo de Martín Bueno, como la información aportada por la técnica constructiva especialmente del Conjunto Industrial IV, en el cual se detecta la presencia en los muros vertebradores de la factoría en vittatum en caliza gris, paramento característico del urbanismo augusteo y julio-claudio de Baelo Claudia. Esta es la hipótesis de trabajo que parece más viable mantener por el momento. Sin embargo, nuestra visión actual de los conjuntos industriales dista mucho de la que debieron tener inicialmente las factorías que nutrian de garvm y salsamenta a la mesa del Princeps. Las sucesivas reformas del complejo han permitido plantear un respeto manifiesto a los ejes maestros del trazado urbanístico, al menos en la parte objeto de estudio intensivo, siendo factible hoy en día mantener que al menos una parte de factorías ha estado en funcionamiento desde el cambio de Era hasta el s. V o incluso VI24] sin grandes alteraciones del espacio industrial, como ejemplifica el Conjunto IV. Es posible plantear adicionalmente que las unidades de producción presentan evidencias de reformas internas fechables en momentos muy avanzados del s. II d.C., en el s. III y durante el Bajo Imperio, caso del C. I y del C.IV, al tiempo que se ha detectado una posible remodelación integral de la parte occidental de la Zona Central del Barrio Industrial, ejemplificada en la amortización del pequeño cardo hacia el sur, mediante la erección de dos grandes complejos industriales en el s. III o más tarde, que son los C. V y C.VI, cuya problemática específica esperamos poder analizar en los próximos años. La técnica constructiva detectada en la totalidad del Barrio Industrial incluye escasos paramentos de vittatum de caliza gris, una frecuencia muy elevada de incertum o pseudo-vittatum de caliza y arenisca de diversa colorimetría, y diversas refacciones y recrecimientos murarios en ostionera, aspectos que confirman la vitalidad arquitectónica de este gran espacio industrial.

Estas propuestas aquí planteadas deben ser tomadas como hipótesis de trabajo en un primer intento por ordenar la información existente sobre la factoría baelonense, para cuya confirmación deberemos esperar a los resultados de futuras actuaciones arqueológicas.

\subsubsection{El modelo de factoría baelonense}

Una cuestión que consideramos conveniente plantear en estas páginas como línea de trabajo para el futuro es la relacionada con la reconstrucción de los diversos espacios industriales desde un punto de vista funcional. Una de las ventajas de las factorías baelonenses es contar con diversas de Unidades de Producción completas cuya planta puede ser estudiada de manera analítica. Este es el único yacimiento del "Círculo del Estrecho" que permite un estudio de estas características, y en el Mediterráneo Occidental probablemente podamos adicionar Lixus en Tingitana y Troia en Lusitania.

[24] Ya hemos comentado en los apartados precedentes la existencia de niveles tardorromanos detectados por $\mathrm{C}$. Domergue en la zona oriental del arroyo de las Vinas, cuyo estudio será publicado exhaustivamente más adelante, en una problemática de ampliación de las cronologías de las factorías baelonenses hasta los últimos siglos de la Antigüedad Tardía. 
Sí queremos insistir en la existencia de diversas Unidades de Producción integradas dentro del Barrio Industrial de la ciudad, y no de un gran complejo industrial al modo de Septem o de Cotta, como comentamos en los párrafos precedentes. La única propuesta de diferenciación entre unas y otras existente hasta la fecha es la planteada por P. Sillières, que alude a la existencia de "grandes et petites conserveries" (Sillières 1995, 179-185). Entre las grandes debemos situar a los conjuntos Industriales C.V y C.VI y entre las pequeñas fábricas de conservas a los cuatro restantes. Como hipótesis de trabajo, y basándonos en la documentación presentada con anterioridad, planteamos que las Unidades de Producción de grandes dimensiones se corresponden con época tardorromana, existiendo bajo ellas los restos de otras más antiguas de similar módulo y dimensiones que las factorías I a IV. Probablemente encontremos fosilizada en esta tendencia un fenómeno de concentración de la propiedad en manos de grandes consorcios industriales o societates a partir del s. III d.C.

Por el momento podemos décir que las factorías baelonenses se ajustan a dos modelos arquitectónicos perfectamente diferenciados, siendo el primer de ellos el más característico en la ciudad (fig. 15).

El primer modelo planimétrico es el de factoría de planta dúplice, caracterizadas por presentar una articulación del espacio en dos zonas, encontrándose las estancias relacionadas con el procesado del pescado industrial en primer lugar y los saladeros al final. Este parece ser el modelo arquitectónico más característico de las factorías baelonenses, pues se constata en la mayor parte de los casos conocidos. Es posible determinar una serie de variables arquitectónicas que permiten diferenciar tres estadios diferentes en la morfología de la planta de estas instalaciones industriales, incrementándose en cada uno de ellos el grado de complejidad de cada una de las partes y su compartimentación interna. Así, tenemos el caso más simple de factoría dúplice ejemplificado por el C. I, con una gran sala diáfana de planta rectangular pavimentada con signinuvm inmediata al acceso al complejo desde el eje viario, con las piletas -seis en este caso- conformando el saladero para el pescado en la parte trasera del inmueble. En estos casos de factorías dúplices simples el espacio anterior es único, siendo las estructuras necesarias para el trabajo escasas (caso de la pileta adosada a uno de los laterales), y normalmente de materia deperible (bancos, mesas...), por lo que no se conservan restos arqueológicos de su existencia. Cuando estas industrias son de mayores dimensiones suelen presentar la plataforma anterior de signinum compartimentada en una serie de habitaciones en las cuales se procede a la organización del espacio por actividades, siendo el modelo en este caso el ilustrado por el C. IV. A pesar de esta subdivisión interna, el esquema arquitectónico es muy similar, encontrándose una vez más las piletas en la parte posterior de la factoría, en este caso con ocho cubetas (figura 15). El caso más complejo de factoría de estas características aparece representado por el C. VI, cuyo esquema compositivo es similar, si bien en este caso la cantidad de habitaciones de la parte anterior suele ser mayor o ser éstas más complejas, y los saladeros de mayor tamaño y envergadura, como ilustran la decena de piletas de este conjunto.

El segundo modelo de factoría es el de planta axial, representado por la $\mathrm{C}$. V, con un espacio intermedio que da acceso a sendas alas laterales con uso diversificado. En el caso específico del C. V, la zona oriental se destinó al procesado del pescado y a su maceración en sal, mientras que probablemente las estancias de la parte occidental tuviesen una 


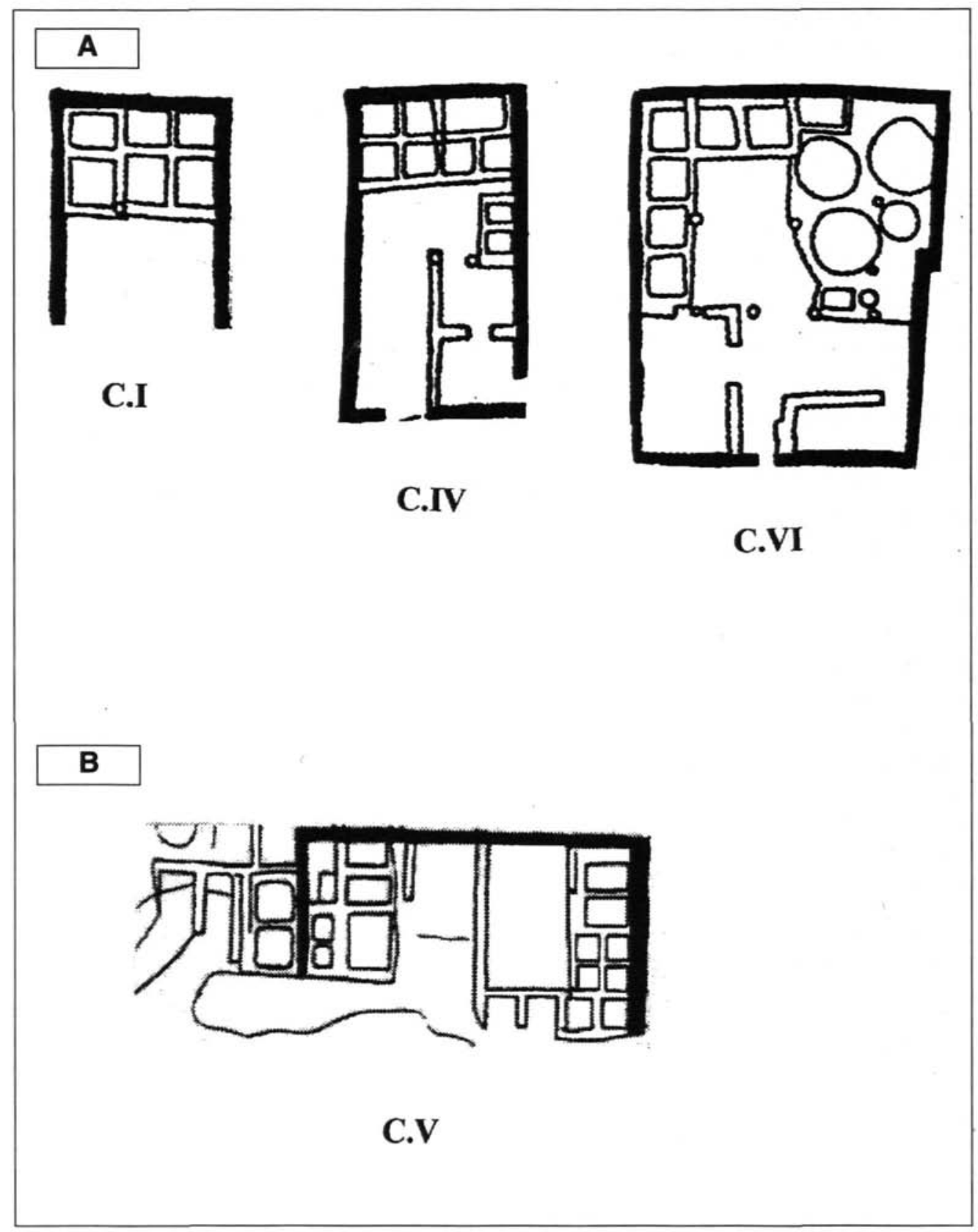

Figura 15. Modelos de plantas arquitectónicas documentadas en la factoría baelonense. A. Factoría de planta dúplice, bien simples (C.I.), complejas, con el espacio anterior compartimentado (C.IV) y con una diversificación integral del espacio (C.VI). B. Factorías de planta centralizada (C.V) 
funcionalidad diversa, probablemente de almacenaje de envases y de otros útiles necesarios para la pesca en las almadrabas.

No encontramos por el momento factorías en Bolonia que se ajusten a esos modelos de planta radial o centralizada respecto a una zona de trabajo intermedia, de los cuales conocemos multitud de ejemplos en casos como el Conjunto 5 de Lixus (Ponsich 1988, 108, fig. 44) o más específicamente las fábricas I y II de Troia (Etienne, Makaroun y Mayet 1994, fig. 55).

Es normal que existan en todos los casos citados aljibes subterráneos para el aprovisionamiento hídrico bajo la plataforma anterior de la factoría, como ilustra el caso del C. IV, si bien en otras ocasiones su inexistencia (como en el C.I) debería ser suplida mediante el aporte hídrico externo. La aparición sistemática de puntales para la sustentación de la techumbre en la totalidad de las factorías, normalmente aprovechando fustes de columna en ostionera o materiales arquitectónicos reutilizados, permite plantear que las factorías tuvieron techumbres posiblemente parciales, limitadas a la zona posterior de los complejos fabriles para garantizar el proceso de maceración de las conservas sin alteraciones derivadas del aporte solar. Las ventanas troncocónicas existentes en el frontal septentrional del ala oriental del C. V'25] (figura 2, supra) permiten confirmar que la aireación estaba asegurada en la factoría, contribuyendo también de esta manera a mantener un ambiente de salubridad en las instalaciones conserveras. Ya hemos comentado cómo es muy probable la existencia de un segundo piso en buena parte de estas factorías de salazones, según se puede deducir de la techumbre adintelada del $\mathrm{C}$. V y de la continuidad del paramento por encima de los $2,5 \mathrm{~m}$ que tendría de altura la primera planta.

Estos aspectos permiten valorar una tendencia a la atomización del proceso industrial de fabricación de salazones y salsas de pescado en Baelo Claudia, pues tras la existencia de esta multiplicidad de factorías debemos buscar a los gestores de dicha actividad, que sin duda alguna debieron ser particulares, los cuales ejercieron una actividad industrial tremendamente lucrativa en la Antigüedad. Tan ventajosas económicamente fueron dichas actividades que incluso las propias residencias privadas de los dueños de estas propiedades se instalaron en el interior del Barrio Industrial, como testimonian la presencia de la Casa del Cuadrante y la Casa del Oeste, propuesta ésta ya planteada por P. París hace casi ochenta años (París et alii 1923, 169).

Esperamos poder continuar en el futuro el estudio integral de las factorías baelonenses, que sin duda alguna constituyen el ejemplo más paradigmático de industria conservera de época romana en toda Hispania, matizando las propuestas aquí planteadas y ampliando el discurso a otros temas no tenidos en cuenta aquí tales como la dinámica comercial de la factoría y el tipo de envases anfóricos utilizados para el envasado de los salsamenta y el garum del "Círculo del Estrecho"[26].

[25] Hemos localizado un vano de similares características en la parte posterior del muro perimetral sur del C. II, intercomunicándolo con el C. III.

[26] Cuestión, esta última, sobre la cual ya se han realizado algunos avances en otros trabajos especializados (Bernal 1996; Bernal 1997). 


\section{BIBLIOGRAFIA}

AGUAROD OTAL, C. (1991): Cerámica romana importada de cocina en la Tarraconense, Zaragoza.

ALONSO VILLALOBOS, C. y NAVARRO DOMÍNGUEZ, M. (1997): "Baelo Claudia. Sus posibilidades portuarias y la navegación por el Estrecho de Gibraltar", III Jornadas de Arqueología subacuática, Valencia, pp. 133-140.

AQUILUÉ, X. (1998): "La cerámica común africana", Ceràmica comuna romana d'època altoimperial a la Península Ibérica. Estat de la questió, Monografies Emporitanes VIII, pp. 61-74.

ARÉVALO, A., BERNAL, D. y ÁLVAREZ, A. (2000): “Actuaciones arqueológicas con motivo del I Curso Internacional de Arqueología Clásica en Baelo Claudia", Caetaria, Revista del Museo Municipal de Algeciras 3, pp. 270-271.

ARÉVALO, A., BERNAL, D. y LORENZO, L. (2001): "Prospecciones arqueológicas en el territorium de Baelo Claudia: nuevos elementos interpretativos", Almoraima 25, Actas de las VI Jornadas de Historia del Campo de Gibraltar (Gibraltar, octubre de 2000), pp. 115-132.

BERNAL CASASOLA, D. (1996): “Transporte de envases vacíos en época romana: a propósito de dos talleres anfóricos béticos de época alto (El Rinconcillo, Algeciras, Cádiz) y bajoimperial (Los Matagallares, Salobreña, Granada)", II Congreso de Arqueología Peninsular, tomo IV, Alcalá de Henares 1999, pp. 359-363.

- (1997): Economía y comercio de la Bética mediterránea y del "Círculo del Estrecho" en la antigüedad Tardía a través del registro anfórico, Tesis Doctoral, Universidad Autónoma de Madrid.

BRODRIBB, G. (1991): Roman brick and tile, Gloucester.

CURTIS, R.I. (1991): Garum and salsamenta. Production and commerce in Materia Medica, Studies in Ancient Medicine 3.

DARDAINE, S. y BONNEVILLE, J.N. (1980): "La campagne de fouilles d'octobre 1979 à Belo", Mélanges de la Casa de Velázquez, XVI, pp. 375-419.

DIDIERJEAN, F. , NEY, F. Y PAILLET, J-L. (1986): Belo III. Le macellum, Madrid.

DOMERGUE, C. (1973): Belo I. La stratigraphie, Madrid.

DOMERGUE, C., NICOLINI, G., NONY, D., BOURGEOIS, A., MAYET, F. Y RICHARD, J-C. (1974): Excavaciones de la Casa de Velázquez en Belo (Bolonia-Cádiz) (Campañas 1966-1971), Madrid, Excavaciones Arqueológicas en España, 79.

ETIENNE, R., MAKAROUN, Y. y MAYET, F. (1994): Un grand complexe industriel a Tróia (Portugal), París.

ETIENNE, R. y MAYET, F. (1970): "Briques de Belo: relations entre la Maurétanie Tingitane et la Bétique au Bas-Empire", Mélanges de la Casa de Velázquez, VII, pp. 59-74.

FURGUS, J. (1907): "Les ruines de Bélon, province de Cadix (Espagne)", Annales de la Société Archéologique de Bruxelles, XXI, pp. 149-160.

- (1908): "Antigüedades romanas en la costa gaditana", Razón y fé, XXI, 2, pp. 205-217.

GARCÍA Y BELLIDO, A, NICOLINI, G., NONY, D. Y DOMERGUE, C. (1968): "Les fouilles de la Casa de Velázquez à Belo-Bolonia (Cádiz) en 1967", Mélanges de la Casa de Velázquez, IV, pp. 393-399. 
LAGÓSTENA BARRIOS, L. (1999): El litoral bispánico. Explotación de sus recursos: origen y evolución bistórica basta el período tardorromano, Tesis Doctoral microfichada, Universidad de Cádiz, Cádiz.

- (2001): La producción de salsas y conservas de pescado en la Hispania romana (siglos II a.C. - VI d.C.), Col.lecció Instrumenta, Universidad de Barcelona, en prensa.

MARTÍN BUENO, M., LIZ GUIRAL, J. y CANCELA RAMÍREZ, M.L. (1984): "Baelo Claudia: sector sur, 1981-1983 (Avance)", Mélanges de la Casa de Velázquez, XX, pp. 487-496.

PARÍS, P. (1917): "Promenade archéologique à Bolonia", Bulletin hispanique, XIX, pp. 221-242.

PARÍS, P. y BONSOR, G. (1918): "Exploration archéologique de Bolonia", BH XX, pp. 77-127.

PARÍS, P., BONSOR, G., LAUMONIER, A., RICARD, R. y MERGELINA, C. DE (1923): Fouilles de Belo (Bolonia, province de Cadiz) (1917-1921). La ville et ses dépendances, París.

- (1926): Fouilles de Belo (Bolonia, province de Cadiz) (1917-1921). La nécropole, París.

PONSICH, M. y TARRADELL, M. (1965): Garum et industries antiques de salaison dans la méditerrannee occidental, París.

PONSICH, M. (1970): Recherches archeologiques a Tangier et dans sa region, París.

— (1976): "À propos d'une usine antique de salaisons à Belo (Bolonia-Cadix)", Mélanges de la Casa de Velázquez, XII, pp. 69-79.

- (1988): Aceite de oliva y salazones de pescado. Factores económicos de Bética y Tingitana, Madrid.

SILLIÈRES, P. (1991): "La maison romaine á Baelo Claudia. Essai de révision des données anciennes", La casa urbana bispanorromana, Zaragoza, pp. 321-326.

- (1995): Baelo Claudia. Une cité romaine de Bétique, Madrid. 